\title{
La colusión como forma de agresión a intereses dignos de protección por el Derecho Penal. Primera aproximación
}

\author{
Osvaldo Artaza Varela*
}

\begin{abstract}
ReSUMeN
El artículo tiene por objeto detectar y analizar ciertos problemas asociados a la justificación de la criminalización de la colusión, al menos en lo que se refiere a la satisfacción de los requisitos que deben entenderse impuestos por el principio de lesividad como límite al ejercicio del ius puniendi. Para esto se ahondará en el problema de los intereses afectados por la colusión que podrían ser jurídico-penalmente relevantes de acuerdo con la función y límites del Derecho penal económico $y$ en las consecuencias que la resolución de tal problema podrían traer para la delimitación de las conductas que debieran ser sancionadas por esta rama del Derecho.
\end{abstract}

Competencia - bienes jurídicos supraindividuales - colusión - criminalización eficiencia económica

\section{Collusion as a form of aggression to interests worthy of criminal law protection. First approximation}

\begin{abstract}
The purpose of this paper is to detect and analyse a number of problems associated with the justification of the criminalisation of collusion, at least for what concern the satisfaction of the requirements imposed by the harm principle as a limit to the ius puniendi exercise. To do so, a detailed discussion about two issues will take place: about the problem of the affected interests by collusion that may be relevant according to the function of economic criminal law, and about the consequences that the solution of that problem may bave to the delimitation of the conducts that should be punished by this branch of the law.
\end{abstract}

Competition - supraindividual legally protected good - collusion - criminalisation economic efficiency

${ }^{1}$ Doctor en derecho y ciencias políticas, Universidad de Barcelona. Profesor de la Facultad de Ciencias Jurídicas y Sociales, Universidad de Talca. Correo electrónico: oartaza@utalca.cl

El presente artículo se enmarca en el proyecto de investigación FONDECYT de Iniciación $\mathrm{N}^{\circ} 11150194$, titulado "Desafíos para la protección penal de la competencia en Chile. Criterios legitimadores y propuesta regulativa". Se agradece la colaboración de los Sres. asistentes de investigación, Luciano Rojas Morán, Germán Acevedo Mundaca y Sebastián Galleguillos Agurto, por sus valiosos aportes en el desarrollo del artículo.

Artículo recibido el 29.8.2016 y aceptado para publicación el 10.7.2017. 


\section{INTRODUCCIÓN Y DELIMITACIÓN DEL PROBLEMA Y PROPUESTA METODOLÓGICA}

$\mathrm{E}$ 1 legislador chileno ha incorporado un nuevo tipo penal que criminaliza lo que

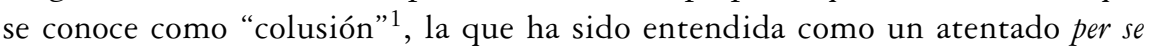
contra la libre competencia, ya que se caracterizaría por restringir o constituir más bien una anulación de esta. Como señalan Zavala y Morales, los competidores "en vez de competir se ponen de acuerdo en no hacerlo y así obtener un beneficio asegurado a costa de quienes le venden..." ". El problema que se analizará a continuación es el de la justificación de la reacción frente a tales ataques contra la competencia por medio del Derecho penal económico (en adelante DPE) ${ }^{3}$, para ello se deberá abordar, brevemente, y a modo de propuesta metodológica, la función que se le asigna a este y los límites a los que debiera estar sujeto.

En términos sencillos, siguiendo la propuesta desarrollada por García Cavero, se puede decir que la función del DPE sería restablecer efectivamente "la identidad normativa esencial de la sociedad en la economía", pero no con el propósito de proteger tal identidad considerada en sí misma, "sino en tanto la organización económica de la sociedad favorece la realización de las personas". Con todo, de acuerdo con el mismo autor, si tal función quiere ser efectiva no podría ser conseguida a toda costa, sino que debe respetar ciertos principios que limitan el ejercicio del ius puniendi ${ }^{6}$, como por

${ }^{1}$ Ver, Ley N $^{\circ} 20.945$, de 30/08/2016, que "Perfecciona el sistema de defensa de la libre competencia”, en artículo $62^{\circ}$, establece: "El que celebre u ordene celebrar, ejecute u organice un acuerdo que involucre a dos o más competidores entre sí, para fijar precios de venta o de compra de bienes o servicios en uno o más mercados; limitar su producción o provisión; dividir, asignar o repartir zonas o cuotas de mercado; o afectar el resultado de licitaciones realizadas por empresas públicas, privadas prestadoras de servicios públicos, u órganos públicos, será castigado con la pena de presidio menor en su grado máximo a presidio mayor en su grado mínimo". Ver también, Wardhaugh, B., Cartels, Market and Crime. A Normative Justification for the Criminalisation of Economic Collusion, Cambridge University Press, Cambridge, 2014, pp. 4 y ss.; Morales Godoy,

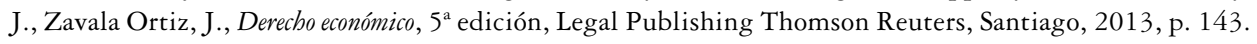

${ }^{2}$ Morales Godoy, J., Zavala Ortiz, J., Derecho económico, p. 143.

${ }^{3}$ Si bien es cierto se podría sostener que tal decisión es de resorte del legislador se han aportado criterios político-criminales para evaluar la legitimidad y racionalidad de tales decisiones. Especialmente relevante, Paredes, Castañón, J., "Los delitos de peligro como técnica de incriminación en el derecho penal económico: bases político criminales", Revista de derecho penal y criminología. num. 11, enero 2003, pp. 99 y ss., quien aborda tal problema desde una perspectiva estrictamente vinculada al Derecho penal económico. Para los fines de este artículo resulta especialmente relevante la propuesta de Diez Ripollés, J. L., La racionalidad de las leyes penales, Trotta, Madrid, 2003, pp. 137 y ss., en la medida que aborda ciertos contenidos de racionalidad de la legislación penal, siendo especialmente relevantes los principios de la protección, los que "debieran regir la elección de los contenidos de tutela por parte del derecho penal”, donde destacan los principios de lesividad, de esencialidad o fragmentariedad, el principio de interés público y el de correspondencia con la realidad.

${ }^{4}$ García Cavero, P., Derecho Penal Económico. Parte general, $3^{a}$ edición, Jurista Editores, Lima, 2014, p. 110. Una visión distinta se desprende de la propuesta de Paredes Castañón, J., "Los delitos de peligro...", pp. 113-114, otorgándole mayor relevancia a la supervivencia del sistema económico.

${ }^{5}$ García Cavero, P., Derecho Penal Económico. Parte general, pp. 111-112.

${ }^{6}$ García Cavero, P., Derecho Penal Económico. Parte general, p. 147. Ver también, Kindhäuser, U., "Acerca de la legitimidad de los delitos de peligro abstracto en el ámbito del Derecho penal económico”, en Hacia 
ejemplo, la exclusiva protección de bienes jurídicos, así como los límites relativos a la delimitación del comportamiento delictivo necesarios para efectuar tal protección ${ }^{7}$. A partir de lo anterior se extraen importantes consecuencias para el objeto de este artículo. Así, en primer lugar, que el contenido del DPE debe ser determinado de acuerdo con la configuración del sistema económico particular del que se trate ${ }^{8}$, lo que no significa, como señala Kindhäuser, que deba ser entendido como un "mero instrumento para mantener un orden económico y sus subsistemas9”. Más bien esto significaría, según Paredes, que para definir el objeto de protección del DPE resultaría imprescindible atender a la realidad sobre la que opera, para así definir los "valores o pautas de conducta" que debiera intentar impulsar ${ }^{10}$.

En segundo lugar, pese a que el DPE se encuentra igualmente limitado por el principio de exclusiva protección de bienes jurídicos, de acuerdo con el cual solo se debiera proteger aquellas características de las personas, cosas o instituciones que sirven al libre desarrollo del individuo en un Estado de Derecho ${ }^{11}$, su propia función explicaría algunas particularidades relativas a este principio limitador. Al respecto, se debe tener en cuenta, como sostiene Feijoo, que el Derecho penal hace tiempo que habría dejado de reaccionar exclusivamente frente a ataques a los intereses básicos de los individuos, y que en la actualidad ya no se pretende garantizar "ciertos mínimos de convivencia, sino que se trata de sociedades muy complejas con un alto grado de juridificación de los problemas sociales", lo que traería como consecuencia la protección de ciertos intereses

un Derecho penal económico europeo. Jornadas en honor del Prof. Klaus Tiedemann (trad. Molina Fernández, F.), Boletín Oficial del Estado, Madrid, 1995, p. 442, según esto, "el derecho penal económico sería legítimo cuando cumple los criterios de legitimidad del Derecho penal en general". Es decir, el DPE también debe responder, entre otros, al principio de exclusiva protección de bienes jurídicos y los límites impuestos por el principio de subsidiariedad y el carácter fragmentario del Derecho penal.

${ }^{7}$ Como señala Kindhäuser, U., “Acerca de la legitimidad de los delitos de peligro abstracto...”, p. 442, la razón que explicaría los reproches que se han efectuado al DPE se debería a "dos circunstancias que son consideradas características del Derecho penal económico: la creación de bienes jurídicos supraindividuales y su protección mediante delitos de peligro abstracto". Ver, en relación con el problema de la legitimidad del DPE, Hernández Basualto, H., "Perspectivas del Derecho penal económico en Chile”, en Revista Persona y Sociedad, vol. XIX, 2005, pp. 108-113.

${ }^{8}$ Así, Zabala, C., Los delitos bursátiles, La Ley (Kindle Edition), España, 2011, pos. 735: "Constituye... una necesidad metodológica en cualquier trabajo sobre Derecho penal económico fijar las bases sobre las que se asienta la economía, es decir, que los resultados de cualquier investigación en el ámbito de la protección penal de la economía dependerán en gran medida del sistema económico que haya adoptado el Estado del que se estudia su tutela penal de la economía”.

${ }^{9}$ Kindhäuser, U., “Acerca de la legitimidad de los delitos de peligro abstracto...”, p. 441 . Al respecto Feijoo Sánchez, B., "Imputación objetiva en el Derecho penal económico y empresarial. Esbozo de una teoría general de los delitos económicos”, en InDret, 2009, p. 5, de acuerdo con el cual, el Derecho penal económico no puede ser entendido como Derecho económico que se sirve de las penas para conducir la economía.

${ }^{10}$ Paredes, Castañón, J., "Los delitos de peligro...", p. 100.

${ }^{11}$ La definición corresponde a Kindhäuser, U., "Estructura y legitimación de los delitos de peligro abstracto", en InDret, 2009, p. 10. 
que reflejarían justamente tal aumento de la complejidad ${ }^{12}$. El correlato de lo anterior en el DPE estaría dado porque este se encargaría, principalmente, de la protección de bienes jurídicos supraindividuales, es decir, sociales, colectivos o intereses de la comunidad $^{13}$. Como señala Paredes, tal peculiaridad estaría dada tanto por el hecho de que se protegerían "objetos (intereses difusos ${ }^{14}$, funciones...) diferentes de lo que le eran habituales ${ }^{15}$ ", así como por la introducción de lo que se conoce como bienes jurídicos intermedios, esto es, "bienes que constituyen la cobertura -y un anticipo en la protección- de otros bienes jurídicos, que serían los verdaderamente relevantes ${ }^{16 ”}$. Esto explica que el contenido de estos intereses no resulte fácil de delimitar y que la doctrina no solo se haya dedicado a proponer categorías que den cuenta de las distintas clases de intereses que protege el DPE, sino que también a resolver el problema de los límites a los que debiera estar sujeta la protección de los mismos ${ }^{17}$. Al respecto, acá se partirá de la base que de la propia definición de bien jurídico a la que se adhiere se desprendería que, al menos, tal protección debiera estar limitada a aquellos intereses "que puedan ser inferidos a partir de intereses particulares" 18 .

${ }^{12}$ Al respecto, Feijoo Sánchez, B., Cuestiones actuales de Derecho penal económico, B de F, Buenos Aires, 2009, p. 206.

${ }^{13}$ Tidemann, K., Manual de Derecho penal económico. Parte general y especial (trad. Hernández Basualto, H.), Tirant lo Blanch, Valencia, 2010, p. 58. Para una justificación de tal forma de protección, García Cavero, P., Derecho Penal Económico. Parte general, p. 150. Ver, al respecto, Martínez-Buján Pérez, Derecho Penal Económico $y$ de la Empresa, Parte General, $5^{\text {a }}$ edición, Tirant lo Blanch, Valencia, 2016, p. 153 y ss.

${ }^{14}$ Un exhaustivo análisis en Vega Gutiérrez, J., Mercado de valores y Derecho penal, B de F, Edisofer s.l., Buenos Aires, 2013, pp. 82-91, quien sostiene que se ha clasificado habitualmente a los bienes jurídicos supraindividuales en aquellos que tutelan un interés social general, es decir, pertenecen a la totalidad de las personas que integran la comunidad y aquellos que tutelan un interés sectorial o difuso, que serían los que protegen un interés de un grupo más o menos amplio de la sociedad, sin que sea a la totalidad de las personas. En contra, Paredes Castañón, J., "Los delitos de peligro...”, p. 130, se refiere a bienes jurídicos supraindividuales y difusos como una misma categoría, realizando una crítica a la clasificación anterior, en tanto no existiría una diferencia relevante, ya que los llamados bienes jurídicos supraindividuales generales se podrían reconducir a intereses sectoriales específicos, como sería el caso de la protección de la competencia.

15 Paredes Castañón, J., "Los delitos de peligro...”, p. 129.

16 Paredes Castañon, "Los delitos de peligro...", p. 129. En p. 134-138, señala que tales bienes son aquellos que no pueden definirse sino con referencia a otro bien jurídico (bien jurídico final). Se protegería el bien intermedio para proteger mejor el bien final, por lo que se exige una relación instrumental estricta, es decir, de medio a fin. Existe una relación instrumental cuando el bien jurídico intermedio carece de entidad propia, por lo que su existencia se justifica única y exclusivamente por referencia al bien jurídico penal. En sentido crítico, en Chile, Carnevali Rodríguez, R., "Algunas reflexiones en relación a la protección penal de los bienes jurídicos supraindividuales”, en Revista Chilena de Derecho, Vol. 27, num. 1, 2000, p. 144.

${ }^{17}$ Al respecto, en forma detallada, Paredes Castañón, "Los delitos de peligro...", p. 130, para quien “cualquier objeto puede constituirse en materia idónea para la protección jurídico-penal” siempre que cumpla ciertas condiciones, a saber, una vinculación a necesidades sociales, justificación moral e instrumental, efecto comunicativo de relevancia sistémica y respecto del principio de subsidiariedad. Para Tiedemann, Manual de Derecho penal económico, p. 66, lo relevante sería la vinculación con el bienestar de la comunidad o de la protección directa de garantías constitucionales.

18 Así, recientemente, Mayer Lux, L., Fernándes Godinho, I., "La estafa como delito económico", en Revista de Derecho de la Pontificia Universidad Católica de Valparaíso, vol. XLI, 2013, p. 189. En otros términos, García Cavero, P., Los delitos contra la competencia, ARA editores, Lima, 2004, p. 6, de acuerdo con el 
En este orden de cosas, el propósito de este artículo es analizar si tal decisión del legislador satisface ciertas exigencias mínimas de legitimidad propias del DPE que debieran ser consideradas a la hora de sancionar nuevas conductas, en la medida que estén relacionadas con el problema de la determinación de los intereses que resultaría legítimo proteger, es decir, a la delimitación de la clase de bienes jurídicos propios del DPE, con el objeto de demostrar que la protección de la competencia económica contra ciertos casos de colusión resultaría legítima, en la medida que protegería un bien jurídico supraindividual fundamental para la promoción de la participación de los ciudadanos en el ámbito de las interacciones económicas. Con todo, se debe dejar en claro que no se abordarán todos los posibles intereses afectados por las diversas formas de colusión que se puedan presentar, por exceder las posibilidades del artículo, sino que se ha elegido uno de los problemas que resultan de mayor importancia en la actualidad, esto es, la afectación de los intereses de los consumidores por los acuerdos para el alza de precios por sobre los precios competitivos, llevados a cabo por productores o distribuidores ${ }^{19}$.

Para tales efectos, y de acuerdo con las particularidades del DPE recientemente descritas y al concepto de bien jurídico que se sigue, se deberá determinar cuáles son aquellas características de la competencia económica que la transformarían en un objeto digno de protección debido a su vínculo con el desarrollo de los individuos, para ello se debe observar necesariamente el papel que juega esta institución en nuestro sistema económico ${ }^{20}$. El propósito de los siguientes apartados es el de constatar los problemas asociados a determinar las características de la institución que debieran servir de base para una eventual propuesta de legitimación de su protección por medio del Derecho penal, para esto se analizará, en primer lugar, el desarrollo del problema de los objetivos asociados a la protección de la competencia desde una perspectiva extrapenal, con el objeto de conectar el problema con la realidad económica en la que opera. Con posterioridad, se analizarán ciertas propuestas de legitimación de la criminalización de la colusión, escogidas por abordar el problema propuesto, esto es, el de los intereses que se verían afectados por la colusión y que debieran ser considerados como dignos de protección por el DPE. Como se pretende demostrar, es posible delimitar adecuadamente los intereses que se afectarían por esta conducta, y tal delimitación tendría importantes consecuencias en lo que se refiere al problema relativo a la determinación de la clase de conductas que debieran incriminarse. En suma, tal labor no solo tendría consecuencias vinculadas

\footnotetext{
cual la protección penal no debiera alcanzar a todos los aspectos constitutivos de la competencia, "sino solo a aquellos que considera esenciales".

${ }^{19}$ Es decir, lo acá dicho no es aplicable al problema de los intereses afectados por conductas como los acuerdos para restringir la competencia afectando el resultado de licitaciones realizadas por empresas públicas o privadas prestadoras de servicios públicos.

${ }^{20} \mathrm{Al}$ respecto Tiedemann, K., "Presente y futuro del Derecho penal económico", Hacia un Derecho penal económico europeo. Jornadas en honor del Prof. Klaus Tiedemann (trad. Suárez González, C.; Lascuraín Sánchez, J.; Cancio Meliá, M.), Madrid, Boletín Oficial del Estado, 1995, p. 33. Bottke, W., "Criminalidad económica y Derecho criminal económico en la República Federal de Alemania” (trad. Arroyo Alfonso, Soledad), en Revista Penal, No 4, 1999, pp. 21 y ss.
} 
a la satisfacción del principio de lesividad, sino que también en lo que respecta a los principios de fragmentariedad y subsidiariedad.

\section{Aproximación EXTRAPENAL A LOS FUndamentos DE LA PROTECCIÓN DE LA LIBRE COMPETENCIA}

Como se dijo anteriormente, el contenido del DPE debe estar asociado en todo momento a la realidad económica en la que opera ${ }^{21}$. Por lo mismo, la intensidad de la valoración de la institución objeto de estudio se definiría analizándola a propósito de la función que juega dentro de las economías de mercado y que justificaría o haría deseable la intervención del Estado para su protección ${ }^{22}$. Como es sabido, en el marco de los sistemas de mercado "el tráfico de los bienes y servicios se determina por la oferta y la demanda existentes ${ }^{23}$ ". Este punto de partida es fundamental porque la eficiencia de este sistema ha estado asociada a que las decisiones más relevantes "relativas a la forma de organizar la propiedad de los medios de producción” y el intercambio de bienes y servicios se adopten, en principio, "en régimen de libertad por los propios operadores privados del sector ${ }^{24}$ ". Con todo, tal eficiencia ha estado asociada a que efectivamente se den algunas condiciones mínimas de funcionamiento del sistema y debido a que no siempre se daría esta situación, ya que el mercado presentaría fallas, se asumiría la necesidad de cierto nivel de intervención estatal ${ }^{25}$. Tal intervención tendría por objeto

${ }^{21}$ Fundamental, Whelan, P., The criminalisation of european cartel enforcement. Theoretical, legal, and practical challenges, Oxford University Press, Oxford, 2014, p. 92. De acuerdo con ello, la problemática asociada a la criminalización de la colusión no puede prescindir de responder, en primer lugar, a las "virtudes del libre mercado para la sociedad”. Asimismo p. 90, y de acuerdo con lo sostenido por el ICN (International Competition Network), la lesividad de la colusión se relaciona con la afectación de los beneficios asociados a la competencia.

${ }^{22}$ En relación con la instauración de un sistema de mercado en Chile, Bassa Mercado, J.,Viera Álvarez, C., "Un nuevo giro hermenéutico de la Corte Suprema en la aplicación del recurso de amparo económico", en Revista de Derecho de la Pontificia Universidad Católica de Valparaíso, XXXVIII, 2012, pp. 663. Ver también, Fermandois Vöhringer, A., Derecho constitucional económico, $2^{\text {a }}$ edición, Ediciones UC, Santiago, 2006. Ferrada Bórquez, J., "La constitución económica de 1980. Algunas reflexiones críticas", en Revista de Derecho, vol. XI, 2000, p. 51, considera que de la Constitución chilena se podría igualmente justificar un sistema de economía social de mercado.

${ }^{23}$ García Cavero, P., Los delitos contra la competencia, p. 3.

${ }^{24}$ Estrada i Cuadras, A., "Presente y futuro del delito de alteración de precios (art. 284 Cp)", en InDret, Barcelona, 2014, p. 6.

${ }^{25}$ Las condiciones necesarias para propender al fomento de las virtudes propias del sistema de mercado serían, de acuerdo con Satz, D., Por qué algunas cosas no deberían estar en venta. Los límites morales del mercado (trad. Salas, H.), Siglo XXI Editores, Argentina, 2015, p. 45, la existencia de una plataforma que los promueva, como por ejemplo, la propiedad, determinadas reglas de intercambio, un contrato y la vigilancia de su cumplimiento. De acuerdo con la autora, “... la existencia de una relación positiva entre determinados mercados y los valores de libertad y eficiencia es contingente: depende, al menos en gran medida, de la plataforma sobre la que dichos mercados se erigen”. Una de las condiciones que deben ser aseguradas sería, justamente, la de la competencia, a través de la prevención de "la tendencia al monopolio", p. 49. Al respecto 
contrarrestar ciertas condiciones, tanto internas como externas, que impedirían que el mercado por sí solo consiga los fines u objetivos que se asocian a este ${ }^{26}$. Por lo mismo, el debate de la justificación de la intervención estatal en el marco del Derecho de la competencia está dado por responder a este problema, es decir, a las condiciones que deben ser mantenidas por el Estado para el cumplimiento de sus fines y cuáles de estos debieran conseguirse por medio de la competencia económica ${ }^{27}$.

Con todo, la tarea propuesta no es una cuestión sencilla, ya que las razones que justifican la protección de la competencia están sujetas a potenciales malos entendidos ${ }^{28}$, debido a que la misma podría vincularse a la consecución de múltiples objetivos ${ }^{29}$, algunos de estos incluso podrían ser incompatibles entre sí $^{30}$.

Duhne, N., Competition Law and Economic Regulation. Making and Managing Markets, Cambridge University Press, Cambridge, 2015, pp. 6 y ss. Así como Paredes Castañón, J. “Los delitos de peligro...”, pp. 101.

${ }^{26}$ De esta manera se entiende que no resulte contradictorio que la Constitución Económica asegure la libertad para desarrollar una actividad económica y al mismo tiempo prohíba conductas como la colusión, en la medida que la libertad económica se encuentra restringida por las normas legales pertinentes que justamente pretenden, en este caso, asegurar que los privados no anulen la competencia. Al respecto, para el ámbito chileno, ver Banfi del Río, C., Responsabilidad civil por competencia desleal. Estudio de derecho chileno y comparado, Legal Publishing, Thomson Reuters, Santiago, 2013, pp. 15 y 16.

${ }^{27}$ Cuando se habla de los fundamentos de la protección de la competencia se está dando cuenta de aquellos beneficios asociados a la misma que debieran tenerse por objetivos a fomentar de forma prioritaria mediante la legislación y la práctica judicial. Para desarrollar este aspecto se dará cuenta, en forma muy breve, de la discusión en sede extrapenal, la que resulta fundamental debido a que es a propósito de la determinación de los objetivos asociados al Derecho de la competencia, especialmente en el ámbito angloamericano y en el de la Unión Europea, donde se presenta un mayor desarrollo de esta cuestión. Ver, al respecto, Berggren, N., "The Benefits of Economic Freedom. A Survey", en The Independent Review, vol. VIII, num. 2, 2003, pp. 194 y ss.

28 Adhar, R., "Consumer, redistribution of income and the purpose of competition law", en ECLR, 2002 , v. 23, p. 341, sostiene por ejemplo que, intuitivamente, podríamos entender las razones por las que protegemos el medioambiental, pero no así con la competencia.

${ }^{29}$ Tal realidad se refleja incluso en la Exposición de Motivos del Proyecto de Ley contenido en Mensaje 009-363, p. 2, que dio inicio al procedimiento legislativo que dio origen a la Ley $\mathrm{N}^{\circ} 20.945$ : "La defensa de la libre competencia es esencial para el desarrollo de Chile. Ella garantiza la existencia de mercados en los cuales impere una competencia basada en los méritos, que permita que las empresas ofrezcan bienes y servicios de mejor calidad, mayor variedad, innovadores y al menor precio posible. Asimismo, propicia una sociedad más justa y democrática, en la cual exista confianza en los mercados y en que quienes cuenten con poder económico no se aprovechen del mismo para cometer abusos que generan serios daños a todos los chilenos".

${ }^{30}$ Para constatar lo anterior basta revisar la literatura relativa a los fundamentos del Derecho de la competencia, o la legislación antimonopólica, a partir de esta se extraen importantes diferencias debido al sistema del que se trate y el momento. Así, por ejemplo, Dabbah, M., International and Comparative Competition Law, Cambridge University Press, Cambridge, 2010, pp. 14 y ss. Desde una perspectiva histórica, diferenciando el sistema antimonopólico estadounidense y el europeo, Motta, M., Competition Policy. Theory and Practice, Cambridge University Press, Cambridge, 2004, pp. 1-38. Ver también las diferencias actuales que se presentan entre el sistema de la Unión Europea y el Reino Unido, Whish, R., Bailey, D., Competition Law, $8^{a}$ edición, Oxford University Press, Oxford, 2015, pp. 521 y ss. No es objeto de este artículo abordar tales diferencias sino solo constatar que los objetivos asociados a tal regulación pueden ser múltiples, así como la detección de los problemas que surgen de tal constatación. Stucke, M., "What is competition?", en Zimmer, D., (editor), The Goals of Competition Law, Edward Elgar Publishing, Cheltenham, UK, Northampton, USA, 2012, p. 30, ejemplifica este problema citando al Tribunal chileno de Defensa de la Libre Competencia, de acuerdo con al cual "el único objetivo de la política de defensa de la competencia es promover y proteger la 
Como explica Waked ${ }^{31}$, el Derecho de la competencia puede ser utilizado para alcanzar determinados resultados sociales o económicos, por lo que es necesario conocer los mismos para facilitar la toma de decisiones de índole político ${ }^{32}$.

Una rápida mirada a la literatura reciente da cuenta de este panorama. Así, por ejemplo, Blair y Sokol han señalado que si se observan los diversos sistemas de protección se podrían identificar múltiples fines que irían modificándose con el tiempo ${ }^{33}$. Para graficar tal divergencia describen los diversos objetivos reflejados en los miembros de la ICN (International Competition Network), los que incluirían asegurar o fomentar un proceso competitivo efectivo, promover el bienestar de los consumidores, aumentar los niveles de eficiencia, garantizar la libertad económica ${ }^{34}$, la protección del papel de las pequeñas y medianas empresas, promover la equidad y la igualdad, promover las opciones del consumidor, lograr la integración de los mercados, facilitar la privatización y liberación de los mercados y promover la competitividad en los mercados internacionales ${ }^{35}$. De acuerdo con lo sostenido por Waked en forma reciente, tales objetivos podrían ser agrupados fácilmente en dos grandes categorías: por una parte aquellos que tenderían a la consecución de la eficiencia económica y aquellos que no estarían asociados a tal objetivo $^{36}$. Al respecto, conviene considerar inmediatamente que si bien se reconoce la posibilidad de fomentar intereses no económicos ${ }^{37}$, estos habrían ido perdiendo fuerza

competencia, pero luego reconocerían que uno de las principales dificultades es definir qué quiere decir libre competencia para la legislación, o definir porqué la competencia misma debiera ser protegida".

31 Waked, D., "Antitrust Goals in Developing Countries: Policy alternatives and Normative Choices”, en Seattle University Law review, vol. 38, 2015, p. 946.

${ }^{32}$ Una de las mayores discusiones que se presentan en este ámbito dice relación, además, con la determinación de si es necesario propender a la consecución de un solo objetivo o si más bien convendría el reconocimiento de objetivos múltiples que pueden ser perseguidos por la misma, estableciendo reglas para la determinación de cuál de estos debe imperar en el caso de que resultaren incompatibles. De acuerdo con Waked, D., "Antitrust Goals in Developing Countries: Policy alternatives and Normative Choices", p. 947 , que se trata de definiciones políticas es evidente si se observa, por ejemplo, la historia estadounidense de protección de la competencia donde la dirección de que adopta el refuerzo de la competencia ha cambiado rotundamente dependiendo de la administración de turno.

33 Blair, R.; Sokol, D., "Welfare standards in U.S and E.U. Antitrust Enforcement", en Fordham Law Review, vol. 81, 2013, p. 2504.

${ }^{34}$ Fundamental, Maier-Rigaud, F., "On the normative foundations of competition law -efficiency, political freedom and the freedom to compete”, en Zimmer, D. (editor), The Goals of Competition Law, Edward Elgar Publishing, Cheltenham, UK, Northampton, USA, 2012, pp. 150 y ss.

35 Blair, R.; Sokol, D., "Welfare standards in U.S and E.U. Antitrust Enforcement", Fordham Law Review, p. 2504.

36 Waked, D. “Antitrust Goals in Developing Countries: Policy alternatives and Normative Choices”, p. 951.

37 Según Waked, proteger a pequeños competidores, o a la industria nacional de la extranjera en aquellos casos en que esta última pudiera ponerla en riesgo, o incluso, la reducción de la pobreza. Señala que este último objetivo sería una manifestación de la eficiencia en la formación de los precios, pero solo en lo que respecta a las necesidades que directamente afectan el bienestar de la población. El efecto esperado sería que, mediante la reducción de precios, se potenciaría la eliminación de las barreras para el ingreso a ciertos mercados, específicamente, aquellos considerados como fundamentales para el desarrollo como, por ejemplo, el de la alimentación o el transporte público. El objeto entonces, sería la disuasión de conductas 
progresiva en la actualidad ${ }^{38}$. Se suele sostener que esta rama del Derecho está determinada por conceptos propios de la economía y que por lo mismo su finalidad debiera definirse sobre la base de criterios provenientes de esta misma. Se señala también que la consecución de otra clase de objetivos, como por ejemplo alcanzar mayores niveles de justicia distributiva, debieran potenciarse con mecanismos más eficientes ${ }^{39}$.

Con todo, de acuerdo con lo señalado por Stucke, el problema que presentaría tal aproximación es que la doctrina a cargo del análisis de la legislación antimonopólica no habría tenido en cuenta un problema conceptual previo que explicaría, en parte, las dificultades asociadas a la determinación de los objetivos de la legislación antimonopólica. Según este autor, si bien es usual que se sostenga que la regulación legal debiera tener por objetivo general la protección de aquello que los economistas entienden por competencia, no se habría tomado en cuenta que los economistas podrían tener una concepción diferente de esta institución de aquella que pudieran tener los políticos o los juristas, y que los economistas tampoco han alcanzado un consenso acerca de lo que debiera entenderse por competencia ${ }^{40}$.

abusivas -relativas a la formación del precio de los bienes- así como incentivar que nuevos competidores participen en la economía, en Waked, D. “Antitrust Goals in Developing Countries: Policy alternatives and Normative Choices", pp. 976-979. Ver también, Lianos, I., "Some reflections on the question of the goals of UE Competition Law”, CLES Working Paper Series, 3/2013, pp. 13 y ss., disponible en web:https://www.researchgate. net/publication/256053279_Some_Reflections_on_the_Question_of_the_Goals_of_EU_Competition_Law

${ }^{38} \mathrm{Al}$ respecto, Dey Degere, The interface between Competition Law, and other EU public policies and their objectives, De Deygere, M. Tesis de magíster, Universidad de Lovaina, año académico 2010-2011, p. 8: “En general, parece haber un consenso en que el derecho de la competencia debería ser aplicado para perseguir eficiencias económicas y el bienestar del consumidor, y que ambos objetivos deberían ser considerados desde una perspectiva económica. En general, la consecuencia más importante que ha resultado del razonamiento más explícitamente económico es el cambio de foco desde la protección de los competidores, hacia la protección de la competencia, y, por tanto, a examinar los efectos de la conducta antes que la forma de la misma" (énfasis en el original). Explica, p. 16, que tal énfasis ha sido la regla general en el sistema estadounidense pero que en forma progresiva se estaría imponiendo en la Unión Europea. Ver también, para esta "aproximación más económica". Véase Vanger, V., "Consumer Welfare, Total Welfare and Economic Freedom-On the normative Foundations of Competition Policy", Freiburg Discussion Papers on Constitutional Economic, 09/3, Institut für Allgemeine Wirtschaftsforschung, pp. 1-2, disponible en web: http://www.eucken. de/fileadmin/bilder/Dokumente/Diskussionspapiere/09_03bw.pdf. Ver también, en relación con los aspectos ideológicos que subyacen a tales decisiones, Lao, M., "Ideology Matters in the Antitrust Debate", Antitrust Law Journal, vol. 79, 2014, pp. 666 y ss.; Maier-Rigaud, F.; "On the normative foundations of competition law -efficiency, political freedom and the freedom to compete", The Goals of Competition Law, Edward Elgar Publishing, Cheltenham, UK, Northampton, USA, 2012, p. 132.

${ }^{39}$ Especialmente mediante políticas públicas financiadas por los impuestos. Ver, Blair, R., Sokol, D., "Welfare standards in U.S and E.U. Antitrust Enforcement", p. 2505; Whelan, P., The criminalisation of european cartel enforcement. Theoretical, legal, and practical challenges, p. 98.

${ }^{40}$ Ver Stucke, "What is competition?”, pp. 28-29. Dentro de su análisis constata distintos conceptos de competencia que, a su vez, dependen del estado del mercado o de las bases teóricas que se adopten (p. 34), dependiendo de si se trata de consumidores y productores racionales (economía neoclásica, pp. 35-37); productores racionales y consumidores con racionalidad limitada (p. 38-42); productores con racionalidad limitada y consumidores racionales (p. 42-44) y; consumidores y productores con racionalidad limitada (p. 44-51), y que en cada uno de ellos se puede identificar fallas de mercado diferentes. 
Por lo mismo, no resulta sencillo clarificar qué se está diciendo realmente cuando se sostiene que promover la eficiencia económica debiera ser considerado como el objetivo prioritario de la legislación antimonopólica ${ }^{41}$. Esta dificultad estaría dada, principalmente, porque cuando se habla de eficiencia se está dando cuenta de un concepto complejo y que presentaría énfasis muy diversos. Colocar el acento en cada uno de estos también traería consecuencias relativas a su función y a las expectativas que surgirían de la misma y, por tanto, a las razones para su protección o fomento. Así, y solo a modo de ejemplo, Whish y Bailey señalan que los beneficios asociados a la competencia serían: a) precios más bajos, b) mejores productos, c) aumento de las opciones para elegir, y d) aumento de la eficiencia en comparación con la que se podría obtener bajo condiciones de monopolio ${ }^{42}$. Pero el concepto de eficiencia puede ser abordado desde diversos niveles, ya que este se compone, al menos, de tres elementos económicos diversos: a) un componente distributivo (allocative efficiency), centrado en los efectos en los consumidores; b) productivo (productive efficiency), relativo al aumento de las ganancias por parte de productores y distribuidores, y; c) el dinámico (dynamic efficiency), representada por los efectos de estimulación de la innovación en razón de los esfuerzos de los competidores por producir nuevos y mejores productos para los consumidores ${ }^{43}$. No resulta fácil definir cuál es la función u objetivos asociados a la competencia económica que debieran resultar prioritarios y, por ello, potenciarse ${ }^{44}$. Simplificando en exceso este problema, se podrían identificar al menos tres tendencias claras ${ }^{45}$. Así, en primer lugar, la de quienes sostienen que se debiera potenciar el bienestar total ${ }^{46}$, ya que el efecto combinado entre la eficacia distributiva y la productiva maximizarían la riqueza de la sociedad ${ }^{47}$. En segundo lugar, la de quienes consideran que se debiera potenciar

${ }^{41}$ Excede a los propósitos de este artículo un análisis detallado de este problema, para una aproximación conceptual ver Kerber, W., "Should Competition Law Promote Efficiency? Some Reflections of an Economist on the Normative Foundations of Competition Law", Marburg Papers on Economics, N 09-2007, pp. 2 y ss., disponible en web: http://papers.ssrn.com/sol3/papers.cfm?abstract_id=1075265.

42 Whish, R., Bailey, D., Competition Law, 8 a edición, Oxford University Press, Oxford, 2015, p. 4, de acuerdo con esto, bajo lo que se conoce como teoría económica neoclásica, el bienestar social se maximizaría bajo condiciones de competencia perfecta. Ver también, Whelan, P., The criminalisation of european cartel enforcement. Theoretical, legal, and practical challenges, 2014, p. 90.

43 Whish, R., Bailey, D., Competition Law, pp. 5-6. Fundamental, Motta, M, Competition Policy. Theory and Practice, Cambridge University Press, Cambridge, pp. 39 y ss.

${ }^{44}$ Ver, en relación con ciertos malentendidos en este debate, Baker, J., "Economics and Politics: Perspectives on the Goals and Future of Antitrust”, en Fordham Law Review, vol. 81, 2013, pp. 2176 y ss.

${ }^{45} \mathrm{Al}$ menos en lo que respecta a la definición del interés prioritario de protección, ya que la mayoría de las posturas analizadas reconocen la necesidad de proteger no solo uno de estos, sino que una pluralidad de objetivos. Como se mencionó anteriormente, la exigencia de optar por un objetivo prioritario se relaciona, por lo general, a los casos en que tales objetivos se vean en conflicto.

${ }^{46}$ Es decir, aquel nivel de la eficiencia que considera los efectos globales que atañen tanto a consumidores como a productores (total welfare). Ver, al respecto, Wright, J., D., Ginsburg, D., "The Goals of Antitrust: Welfare Trump's Choice", en Fordham Law Review, vol. 81, 2013, pp. 2405 y ss. Ver también Kaplow, L., "On the Choice of Welfare Standards in Competition Law", en Harvard Law School, Discussion Paper, n. 693, p. 19. Disponible en web: http://www.law.harvard.edu/programs/olin_center/papers/pdf/Kaplow_693.pdf.

${ }^{47}$ Whish, R., Bailey, D., Competition Law, p. 5. 
principalmente el bienestar del consumidor ${ }^{48}$, porque así se potenciaría el consumo y, por esta razón, también la producción y, en tercer lugar, la de quienes creen que se debiera potenciar la eficiencia dinámica, especialmente por los beneficios a largo plazo que tal decisión acarrearía ${ }^{49}$.

Debido a que tradicionalmente se han asociado los efectos lesivos de la colusión a la eficiencia distributiva, se abordará en forma breve el contenido de esta. Lo primero que se debe tener en cuenta es que tal componente distributivo ${ }^{50}$ se tiende a equiparar en la actualidad a lo que los economistas entienden por "bienestar del consumidor" 51 ", tendencia que sería considerada como la corriente dominante en lo que respecta a la determinación de los objetivos prioritarios de la legislación antimonopólica ${ }^{52}$. Esta variante, como explica Ayal, recibe su nombre por su foco en la distribución de los bienes, ya que la eficiencia se conseguiría distribuyendo cada bien a su "usuario más eficiente $e^{53}$ ", correspondiente a aquel que esté dispuesto a pagar más por el mismo. Tal valoración puede ser efectuada debido a preferencias personales o mediante la comparación de las ventajas obtenidas por la utilización del bien, pero en ambos casos se estaría utilizando el bien en la mejor forma posible, lo que redundaría en un beneficio para toda la sociedad ${ }^{54}$. Ahora, y desde un punto de vista económico, se ha definido el bienestar del consumidor como equivalente al "excedente del consumidor", es decir,

${ }^{48}$ Desde una perspectiva conceptual, Cseres, K., "The controversies of the Consumer Welfare Standard”, en The Competition Law Review, vol. 3, 2007, pp. 124 y ss. Ver también. Kikwood, J., Lande, R., "The Fundamental Goal of Antitrust: Protecting Consumers, Not Increasing Efficiency", en Notre Dame Law Review, vol. 84, 2008, pp. 197 y ss.

${ }^{49}$ Según Waked, D., “Antitrust Goals in Developing Countries: Policy alternatives and Normative Choices”, pp. 949, lo anterior sería especialmente recomendable para los países en desarrollo.

${ }^{50}$ Se han propuesto dos formas de entender lo que se conoce como eficacia distributiva, por una parte, por su asimilación a lo que se conocer como total welfare, caracterizada por evaluar los efectos de la política pública en el bienestar total producido tanto en consumidores como productores, por tanto, centrados en un concepto de eficacia económica total, y una segunda postura que limita los criterios evaluativos en los efectos esperados en los consumidores. Al respecto, fundamental, Daskalova, V., "Consumer Welfare in EU Competition Law: What Is It (Not) About?", en The Competition Law Review, vol. 11, 2015, pp. 133 y ss.

51 Daskalova, V., "Consumer Welfare in EU Competition Law: What Is It (Not) About?", p. 136, sobre todo en relación con los problemas de vaguedad asociados a este concepto.

52 Waked, D., "Antitrust Goals in Developing Countries: Policy alternatives and Normative Choices”, p. 952, Se deben considerar ciertos los malos entendidos que se pueden generar por este concepto, asociadas a la confusión con criterios propios del total welfare. Así por ejemplo, Ayal, A., Fairness in Antitrust: Protecting the Strong from the Weak (Kindle Edition), Hart Publishing, Oxford and Portland, Oregon, 2014, pos. 1006, sostiene que el término bienestar del consumidor se ha prestado a malos entendidos debido a que muchos lo equipararían a la eficacia distributiva general como sinónimo de lo que se conoce como "bienestar total o general" (total welfare), mientras otros pondrían el acento en el consumidor más que en los productores. Con todo, y de acuerdo con lo sostenido por Daskalova, aquello que deba entenderse por bienestar del consumidor está lejos de ser autoevidente, Daskalova, V., "Consumer Welfare in EU Competition Law: What Is It (Not) About?”, p. 134. Así, por ejemplo, no hay acuerdo entre los economistas acerca de qué debe entenderse por consumidor, lo que por consiguiente está vinculado al problema de la clase de consumir que debiera protegerse, desde el propio punto de partida de esta aproximación, es decir, la eficiencia.

53 Ayal, A., Fairness in Antitrust: Protecting the Strong from the Weak, pos. 1030.

${ }^{54}$ Ayal, A., Fairness in Antitrust: Protecting the Strong from the Weak, pos. 1030. 


\section{la diferencia entre lo que los consumidores estaban dispuestos a pagar por un producto y lo que} en definitiva terminan pagando. Lo que se debiera prevenir con la intervención estatal es que los competidores redujeran los niveles de tal eficiencia, debido a la disminución de los consumidores que accedan al bien en particular y vean satisfecha su demanda, aumentando así la ineficiencia distributiva ${ }^{55}$.

En este sentido, y de acuerdo con lo señalado en forma tradicional, la colusión afectaría a la competencia debido a que quienes acuerdan no competir actuarían en el mercado como si fueran partes de un solo monopolio, reemplazando la competencia por la coordinación ${ }^{56}$. Como es bien sabido, el precio monopólico podría llegar a ser mayor que el precio competitivo, lo que traería como consecuencia diversas formas de reducción del bienestar, ya sea por una reducción del excedente del consumidor ${ }^{57}$ o por un aumento de lo que se conoce como pérdida irrecuperable de eficiencia ${ }^{58}$, reflejado en el aumento de los consumidores que no verían satisfecha su demanda ${ }^{59}$. Pero además de tales efectos de pérdida de bienestar, las conductas monopólicas serían fuente de pérdidas para toda la sociedad mediante dos clases de ineficiencia productiva ${ }^{60}$. En primer lugar, se vería desincentivada la innovación de los productos, ya que debido al acuerdo cooperativo entre

${ }^{55}$ Waked, D., "Antitrust Goals in Developing Countries: Policy alternatives and Normative Choices", p. 953; Daskalova, V., "Consumer Welfare in EU Competition Law: What Is It (Not) About?", p. 136.

${ }^{56}$ Wardhaugh, B., Cartels, Market and Crime. A Normative Justification for the Criminalisation of Economic Collusion, Cambridge University Press, Cambridge, 2014, p. 7.

57 Whelan, P., The criminalisation of european cartel enforcement. Theoretical, legal, and practical challenges, p. 90. Señala el autor, en p. 93, que la consideración de este efecto como un "daño" debe responder a una eventual crítica dada por el impacto ínfimo que, por lo general, tendría la colusión en los consumidores individualmente considerados. Por lo que incluso se le ha llegado a considerar como un "delito sin víctimas". Se debe tener en cuenta que incluso las víctimas podrían ni siquiera enterarse de que se han aumentado los precios por encima del precio competitivo.

${ }^{58}$ Conocido también como "pérdida de peso muerto". De acuerdo con Wardhaugh, B., Cartels, Market and Crime. A Normative Justification for the Criminalisation of Economic Collusion, p. 8, como el precio monopólico supera el precio competitivo, aquellos consumidores que habrían estado dispuestos a pagar este último, pero no el primero por exceder sus expectativas, renunciarían a la adquisición del bien, dejando insatisfecha tal demanda.

59 Wardhaugh, B., Cartels, Market and Crime. A Normative Justification for the Criminalisation of Economic Collusion, p. 7. Ver también, Dunne, N., Competition Law and Economics Regulation. Making and Managing Markets, Cambridge University Press, Cambridge, 2015, p. 9, acerca de la noción de fallas en la distribución como una clase de falla de mercado y la justificación, en tales casos, de intervención del Estado. Explican, Whish, R., Bailey, D., Competition Law, p. 5, que bajo condiciones de competencia perfecta los recursos económicos serían distribuidos entre diversos bienes y servicios en forma tal que no fuera posible mejorar la situación de nadie sin tener que, al mismo tiempo, tener que empeorar la situación de alguien más. Estos bienes y servicios serían distribuidos entre los consumidores de acuerdo con el precio que estén dispuestos a pagar, lo que permitiría que a largo plazo los precios equiparen lo que se conoce como costos marginales de producción, los que incluirían un margen suficiente de ganancias para incentivar al productor a invertir su capital en la industria determinada, pero no más que eso. Tal aspecto de la eficiencia se vería afectado por conductas como la colusión.

${ }^{60}$ Wardhaugh, B., Cartels, Market and Crime. A Normative Justification for the Criminalisation of Economic Collusion, p. 9. Con todo, y de acuerdo con los diversos componentes de la eficiencia ya analizados, algunos de estos efectos corresponderían, más bien, a lo que se conoce como eficiencia dinámica. Ver, en relación a la potencialidad lesiva, Whelan, P., The criminalisation of european cartel enforcement. Theoretical, legal, and practical challenges, pp. 90-95. 
productores que garantizaría sus ganancias, cualquier incentivo para mejorar la calidad de sus productos desaparecería. En segundo lugar, otro de los efectos indeseables asociados a la colusión estaría dado por la disminución de los incentivos para la innovación de los procesos productivos necesarios para poder mejorar la calidad de los productos.

Sin embargo, y como se verá a continuación, la doctrina especializada sostiene, por lo general, que estas consecuencias lesivas no serían suficientes para justificar la utilización del Derecho penal, lo que parece bastante razonable si se considera que no se ha dado cuenta aún de las características de tal institución que la vincularían con el desarrollo de los individuos, ya que el enfoque que se describió se concentra, principalmente, en los efectos vinculados al mero aumento de la ineficiencia económica. Por lo mismo, se analizarán a continuación argumentos para la criminalización que responderían a la reacción frente a efectos lesivos de mayor intensidad o gravedad en la medida que se encontrarían vinculados a intereses de los individuos, así como a razones que reflejarían el mayor reproche moral que supone tal conducta, en forma similar a otras conductas prohibidas por esta rama del Derecho ${ }^{61}$.

\section{INTERESES DE RELEVANCIA JURÍDICO-PENAL QUE SE VERÍAN AFECTADOS POR LA COLUSIÓN}

El propósito del presente apartado es dar cuenta de ciertas posiciones de la doctrina cuyo objeto es detectar los intereses que se verían afectados por la colusión. Estas se han escogido porque tienen en común el hecho de que no se concentrarían en los efectos globales para la economía, sino en los efectos lesivos para los ciudadanos y, además, porque entre ellas mismas representan aproximaciones totalmente distintas al problema, demostrando la complejidad del mismo ${ }^{62}$. La primera de estas consideraría que lo medular de la protección de la competencia de la colusión estaría dada porque sería una forma de proteger intereses individuales, los que serían el verdadero objeto de protección, mientras que la segunda, sostendría que los efectos asociados a la colusión que justificarían su criminalización estarían asociados a la afectación de la institución propiamente tal y la función asignada a la misma ${ }^{63}$.

${ }^{61}$ Para tal equiparación ver, Whelan, P., The criminalisation of european cartel enforcement. Theoretical, legal, and practical challenges, pp. 89-108, específicamente mediante la comparación de esta conducta con formas de agresión propias del ámbito angloamericano como stealing, deception y cheating. También, Haines, F., Beaton-Wells, C., "Ambiguities in Criminalizing Cartels. A Political Economy”, en Brit. J. Criminol., 52, 2012, pp. 962 y ss.

${ }^{62}$ Desde la perspectiva del tratamiento que se le ha dado a este problema en el ámbito angloamericano serán especialmente relevantes los argumentos relativos al "daño social” (social harmfulness) y a la "ilicitud moral" (moral wrongfulness) asociados a esta conducta, los que han sido vinculados a un nivel "retributivo" de la justificación de la criminalización de la colusión. En relación con estas categorías, fundamental, Green, S., Mentir, hacer trampas y apropiarse de lo ajeno. Una teoría moral de los delitos de cuello blanco (trad. Agustina Sanllehí, J., Amorós Bas, M., Ortiz de Urbina Gimeno, I.), Marcial Pons, Madrid, 2013, pp. 68 y ss.

${ }^{63}$ No es objeto de este artículo agotar este debate, sino solamente dar cuenta de ciertas alternativas que parecen especialmente relevantes por las diferencias que presentan, ya que en la terminología más propia de la discusión respecto del bien jurídico en el DPE ya descrita, la primera postura abogaría porque 
La primera de las posturas que se analizará sostiene que para justificar la criminalización de la colusión se debe entender que tal conducta es asimilable valorativamente a lo que se conoce en el ámbito angloamericano como stealing, esto es, según Green, "violar de algún modo fundamental el derecho de propiedad de otra persona ${ }^{64 " . ~ E l ~ f u n-~}$ damento de tal equiparación vendría dado por el efecto de aumento de precios propios de la colusión, ya que como resultado de la anulación de la competencia los consumidores pagarían más de lo que habrían tenido que pagar en condiciones adecuadas, con la consiguiente disminución de su capacidad adquisitiva. De acuerdo con Kirwood y Lande, de esta forma se estaría afectando el derecho de propiedad de los consumidores sobre tal excedente, lo que se produciría mediante su apropiación por parte de las empresas con poder de mercado. Entonces, la colusión debiera ser criminalizada por constituir una forma de explotación que en forma injusta transferiría la riqueza de los consumidores a esas empresas $^{65}$. El Estado debiera intervenir con el objeto de proteger a los consumidores, debido a que esta sería la función prioritaria de la legislación antimonopólica, ya que lo que se espera del mercado competitivo es que en razón de la competencia entre los oferentes, para poder captar a los respectivos clientes, opere una fijación de precios que tienda a su baja y conductas como la colusión anularían la función esperada de distribución más eficiente de recursos, no optimizando el bienestar de los consumidores.

Con todo, esta postura presentaría problemas de diverso tipo que deben ser tenidas en cuenta. Su corrección supone que de las reglas de fijación de precios propias del mercado se derivarían no solo efectos positivos para la economía (más consumo y, por esta razón, mayor producción correlativa), sino que también expectativas de protección del excedente del consumidor reforzados por derechos de propiedad sobre este, lo que al parecer dan por hecho sin recurrir a puntos de apoyo jurídicos ${ }^{66}$. Como señala Wardhaugh,

se trataría de la protección de bienes jurídicos intermedios o mediatos, mientras que la segunda de estas, de la protección de bienes jurídicos supraindividuales vinculados a la protección de determinada función.

${ }^{64}$ Green, S., Mentir, hacer trampas y apropiarse de lo ajeno..., p. 133. Para un panorama general de tal equiparación de la colusión con los delitos contra la propiedad ver, Whelan, P., The criminalisation of european cartel enforcement. Theoretical, legal, and practical challenges, pp. 96-101.

${ }^{65}$ Kikwood, J., Lande, R., "The Fundamental Goal of Antitrust: Protecting Consumers, Not Increasing Efficiency", p. 192. Tal propuesta se entiende porque, según los mismos, la función de la protección de la competencia no vendría dada por incrementar las ganancias o riqueza de la sociedad y que en casos en que estos dos objetivos entren en conflicto (aumentar riquezas versus el interés de los consumidores), los tribunales estadounidenses habrían decidido siempre priorizar la protección del consumidor por sobre la eficiencia económica. Sostienen, eso sí, que el único objetivo adicional de legislación sería proteger a los pequeños vendedores de la fijación de precios y otras prácticas anticompetitivas de los compradores, objetivo que se vería limitado, en todo caso, debido a que se aplicaría solo cuando las acciones judiciales respectivas no deriven o causen que los consumidores deban pagar precios "supracompetitivos".

66 Por el contrario, en Chile Hernández Basualto, H., "La punibilidad de la colusión (secreta) de precios en el derecho chileno", en Política Criminal, vol. 7, num. 13, pp. 147-167, aunque para fines muy diversos, esto es la interpretación del art. 285 del Código penal chileno, propone una forma de justificar la sanción penal que no presentaría el problema descrito, en la medida que por medio de la colusión, cuando es desconocida por los consumidores, podría ser entendida como una forma de engaño concluyente desde la perspectiva de los delitos contra intereses patrimoniales. Por lo mismo se entiende que los casos en que el consumidor pague más de lo debido, podrían ser entendidos como un perjuicio patrimonial. El fundamento 
tal postura partiría de la base que a partir del funcionamiento del mercado, es decir, de las interacciones propias de este, emanarían derechos de propiedad, cuando en realidad lo correcto sería lo inverso ${ }^{67}$. Es decir, los derechos de propiedad estarían claramente definidos por el ordenamiento jurídico respectivo, antes que se efectúen las transacciones económicas propias de cada mercado. Como se suele señalar desde la teoría económica, serían las relaciones de propiedad, previamente establecidas, las que darían paso a lo que se conoce como economías de mercado ${ }^{68}$. Por el contrario, la postura criticada asumiría que serían conceptos propios del funcionamiento de los mercados, como son los de excedente del consumidor o del productor, los que definirían estos derechos de propiedad ${ }^{69}$.

Por otra parte, Wardhaugh sostiene que esta aproximación sería incorrecta por un segundo aspecto. A diferencia de los casos de apropiación, el comprar bienes a quienes están coludidos debiera seguir siendo considerado, en la mayoría de los casos, como intercambios voluntarios. Según este autor, a partir de tal constatación se ha sostenido que este efecto de la colusión, es decir, el del aumento del precio, sería moralmente menos reprochable que otros efectos lesivos asociados a tal conducta. En el fondo, si bien es cierto se reconoce que la colusión afecta a los consumidores en la medida que genera una disminución de la capacidad adquisitiva de estos, no queda claro por qué razón tal efecto debiera ser considerado como un delito o, más bien, por qué tales consumidores debieran ser considerados como víctimas de un delito. Wardhaugh tiene razón al sostener que el mero hecho de constatar que se podría haber pagado menos por un bien, o incluso que en definitiva no se pueda adquirir porque es más caro de lo que el consumidor estaba dispuesto a pagar, no es todavía una buena razón para reaccionar por medio del Derecho penal. El problema se presentaría porque el análisis acerca de las razones para proteger el excedente del consumidor, o evitar el aumento de los consumidores que no pueden adquirir el bien, es todavía demasiado vago ${ }^{70}$. Junto con lo anterior, se le podría criticar su excesiva atención al daño individual causado por la colusión, siendo que, como se

no está dado entonces por la apropiación del excedente del consumidor sino en que el pago extra, efectuado por el consumidor, sería producto de un engaño penalmente relevante.

67 Wardhaugh, B., Cartels, Market and Crime. A Normative Justification for the Criminalisation of Economic Collusion, p. 38. El error, según este autor, radicaría en asumir que estos términos supondrían o implicarían la propiedad de sus beneficiarios. Por ende, tal equivalencia con la apropiación debiera considerarse falaz.

${ }^{68}$ Ver Debra S., Por qué algunas cosas no deberían estar en venta. Los límites morales del mercado (trad. Salas, H.), Siglo XXI Editores, Argentina, 2015, p. 32, "el funcionamiento de todos los mercados depende de las leyes de propiedad existentes..." (énfasis en el original).

69 En forma diversa Whelan, P., The criminalisation of european cartel enforcement. Theoretical, legal, and practical challenges. p. 97, de acuerdo con esto, la tendencia internacional actual de priorizar como estándar el bienestar del consumidor, por sobre el del "bienestar total", puede ser interpretado, eso sí, como un punto de apoyo a esta postura. Con todo, reconoce varios elementos problemáticos vinculados a este punto de partida que deben ser considerados en un análisis más profundo de esta eventual justificación. Por otra parte, tal punto de partida obligaría, además, a sancionar exclusivamente los casos en que el "cartel” se logre implementar y no solo quede en estado de acuerdo, ya que exige que en definitiva se consiga el efecto de ineficacia distributiva respectivo.

${ }^{70}$ Wardhaugh, B., Cartels, Market and Crime. A Normative Justification for the Criminalisation of Economic Collusion, p. 40. 
ha señalado, muchas veces los efectos en la reducción del excedente del consumidor, individualmente considerados, serían ínfimos, y que muchas veces estos ni siquiera se percatarían del aumento de los precios del que son víctimas. Por estos motivos, el daño social causado por esta conducta debiera determinarse atendiendo a sus efectos en toda la comunidad más que en los efectos lesivos que se generen para los individuos ${ }^{71}$. Sobre todo considerando que los efectos de la colusión pueden ser realmente significativos si se consideran en términos colectivos o totales (tomando en cuenta, por ejemplo, el total de ganancias que conlleva para sus autores $)^{72}$.

Pero además, si se considera la discusión en sede extrapenal ya abordada, relativa a los fundamentos de protección de la competencia, se podrían extraer argumentos adicionales para poner en duda la corrección de esta primera aproximación. En primer lugar, se podría cuestionar que se deba priorizar necesariamente los intereses de los consumidores por sobre los intereses de los productores, pero también se podrían tomar en cuenta diversos factores que complejizan el análisis de la eficiencia distributiva, como pueden ser lo difusa que puede resultar la clasificación entre consumidores y productores, o la elección entre la clase de consumidores que se debieran proteger ${ }^{73}$. En segundo lugar, no se puede ignorar que si se considera que los consumidores son propietarios del excedente respectivo sin ninguna limitación, se debe concluir que el único objetivo de la regulación de la competencia económica sería el de asegurar que no disminuya este excedente, aun si de esto deriva una merma significativa en los otros niveles de eficiencia.

Sin embargo, desde la literatura económica se han dado buenas razones para evitar que la pretensión de que no se vea disminuido el excedente del consumidor, no esté sujeta a algunas limitaciones en aras a la consecución de mayor eficiencia dinámica. Así, por ejemplo, se ha sostenido que la disminución del excedente del consumidor o de su bienestar puede ser temporal si es que la justificación de tal disminución, por el aumento de precios, trae como consecuencia el desarrollo e innovación tecnológica, la que en definitiva puede redundar en mayores beneficios para la sociedad ${ }^{74}$. Aun asumiendo la importancia del efecto reductivo del precio para el consumidor, y que el mismo puede ser reconocido perfectamente como una expectativa normativa digna de protección, esta no es absoluta sino que se ve limitada por la necesidad de perseguir la consecución de otros objetivos también valiosos. Por último, esta postura tampoco respondería a la potencialidad lesiva de la colusión en su sentido más amplio en la medida que solo se concentra en los casos de disminución del excedente del consumidor, sin atender a un

${ }^{71} \mathrm{Al}$ respecto, Whelan, P., The criminalisation of european cartel enforcement. Theoretical, legal, and practical challenges, p. 94.

${ }^{72}$ Whelan, P., The criminalisation of european cartel enforcement. Theoretical, legal, and practical challenges, p. 94.

${ }^{73}$ Ver Whelan, P., The criminalisation of european cartel enforcement. Theoretical, legal, and practical challenges. p. 98, Daskalova, V., "Consumer Welfare in EU Competition Law: What Is It (Not) About?”, pp. 138-140, quien da cuenta de los diversos problemas que surgen a la hora de definir qué se entiende por consumidor desde esta perspectiva.

${ }^{74}$ Waked, D., "Antitrust Goals in Developing Countries: Policy alternatives and Normative Choices”, p. 959; Daskalova, V., “Consumer Welfare in EU Competition Law: What Is It (Not) About?”, pp. 137-138. 
importante efecto asociado a la misma, esto es, el de los consumidores que en definitiva no podrían ver satisfecha su demanda (es decir, acceder al bien o servicio).

Estos argumentos demostrarían lo poco conveniente de concentrarse, para efectos de justificar su criminalización de cara a las exigencias impuestas por el principio de lesividad, en los efectos lesivos de la colusión directos para los consumidores, debido a las importantes diferencias que existen al respecto. Por los mismo, se abordará a continuación una postura alternativa; de acuerdo con ello, para la justificación de la utilización del Derecho penal sería más adecuada la referencia a la afectación de intereses supraindividuales asociados a la función que cumpliría la competencia.

Esta alternativa es la propuesta efectuada por Wardhaugh, el que justificaría la criminalización de la colusión a partir de lo que denomina "afectación a la justicia distributiva como institución ${ }^{75}$ ". De acuerdo con el autor, lo primero que debe ser considerado es que la colusión no afectaría a los individuos, o a un partícipe individual del mercado, sino que al mercado como institución en lo que respecta a su función de distribución de bienes y servicios, esto es, afectaría a su componente de justicia distributiva. La relación que se establece entre tal institución y los intereses de los individuos igualmente es clara, ya que como señala él mismo, el mercado debe ser considerado como la institución en la que los individuos distribuyen y adquieren aquellos bienes necesarios para la consecución de objetivos fundamentales para sus propias vidas.

Tal conclusión se extraería del importante rol distributivo que jugaría el mercado en sociedades liberales. De acuerdo con su opinión, y siguiendo en esto la teoría de la justicia de Rawls, "los ciudadanos, bajo determinadas condiciones de igualdad (como la del "velo de la ignorancia") escogerían el mercado justamente porque protegería y promovería la libertad de quienes participan en este ${ }^{76}$. Como se puede apreciar, tal postura parte de la base que, desde una perspectiva de la justicia, las decisiones distributivas que derivan del mercado serían las más justas, y no exclusivamente las más eficientes, ya que cualquier otra forma de distribución, por ejemplo, la que se pudiera efectuar por el Estado, no podría ser llevada a cabo "sin una interferencia significativa en la vida de los ciudadanos ${ }^{77}$ ".

Es especialmente relevante que el autor sostenga que a partir de acá emanen ciertas expectativas relativas al comportamiento de los demás en las interacciones del mercado. Al igual como el ordenamiento jurídico define y protege ciertas expectativas de comportamiento, el mercado establece las suyas. Como consecuencia de este rol social distributivo del mercado, se derivarían expectativas razonables relativas a la justicia

${ }^{75}$ Wardhaugh, B., Cartels, Market and Crime. A Normative Justification for the Criminalisation of Economic Collusion, pp. 43-48.

76 Wardhaugh, B. Cartels, Market and Crime. A Normative Justification for the Criminalisation of Economic Collusion, pp. 44-45. Desde el punto de vista rawlsiano (adoptado por Wardaugh), el mercado sería la institución de la justicia distributiva. "El experimento de Rawls", sostiene Wardaugh, "muestra que el mercado sería elegido por aquellos en condiciones de justicia (fairness) (el velo de la ignorancia), precisamente porque promueve y protege la libertad de quienes en él participan”.

77 Wardhaugh, B., Cartels, Market and Crime. A Normative Justification for the Criminalisation of Economic Collusion, p. 44. 
y corrección de cómo se debieran llevar a cabo sus transacciones ${ }^{78}$. Por lo mismo, los efectos lesivos asociados a la colusión no tendrían que ver con la eficiencia económica como es expresado habitualmente, sino más bien con sus efectos erosivos en la confianza en la corrección del mercado como sistema de transferencia de bienes y servicios y distribución de los mismos. Así, quienes intervienen en intercambios particulares esperan que los mismos se efectúen en forma voluntaria, que la información relevante sea conocida, que se tenga una certeza razonable acerca del objeto de la transacción, etc. Pero, a su vez, también se espera que dichos intercambios particulares o individuales se lleven a cabo en determinado contexto o ambiente que facilite que se desarrollen en esas condiciones de corrección o equidad. Estas condiciones de equidad exigirían que los partícipes puedan estar el tanto y puedan consentir en las reglas propias de los actos. Esto es, que las reglas no sean desconocidas para quienes participan, o que solo puedan ser conocidas por algunos de los interesados en el intercambio.

En este sentido, la conducta de quienes se coluden vulneraría o afectaría las legítimas expectativas de participar en un contexto equitativo de transacciones económicas (fair environment for exchange). Por medio del acuerdo en los precios, cantidad de producción o cuotas de mercado mediante una apariencia de competencia, quienes se coluden "estarían creando reglas ocultas, conocidas solo por ellos mismos ${ }^{79}$ ”, que afectarían a todos los que pretenden interactuar en tales intercambios. Una buena analogía para entender los efectos lesivos de estas conductas puede encontrarse en los casos de competencias deportivas previamente arregladas. De acuerdo con esta postura, un espectador de un evento deportivo esperaría que uno de los contendientes gane el encuentro debido a sus propias habilidades, o incluso por mediación de la suerte, pero en ningún caso a que los resultados estén previamente determinados o arreglados. Dichos acuerdos cuestionarían la credibilidad e integridad del deporte en cuestión. Asimismo, quienes se coluden anulando la competencia, predeterminarían el mercado en forma tal que se podría cuestionar la integridad y confiabilidad de este. Desde esta perspectiva se podría decir que la colusión resultaría especialmente grave o intolerable desde una perspectiva moral, porque constituiría una forma de engaño ${ }^{80}$, en la medida que, por una variedad de técnicas se podría hacer creer a los consumidores que el precio que están pagando no es

${ }^{78}$ Como señala Wardhaugh, B., Cartels, Market and Crime. A Normative Justification for the Criminalisation of Economic Collusion, p. 44: "nosotros, como participantes del mercado, tenemos expectativas de cómo deben ser conducidas las transacciones del mercado".

79 Wardhaugh, B., Cartels, Market and Crime. A Normative Justification for the Criminalisation of Economic Collusion, p. 45. Como parece extraerse de lo señalado por Whelan, P., The criminalisation of european cartel enforcement. Theoretical, legal, and practical challenges, p. 100, una aproximación tal, que debiera conectarse con una forma particular de agresión como es el engaño (deception). La consecuencia de esa equiparación es que solo serían relevantes los casos en que la colusión (y su correlativo efecto en el precio) permanece secreta para el resto de los partícipes. Al respecto da cuenta de la realidad del Reino Unido (sección 188 Enterprise Ac 2002), que provee de una excepción para quienes publiciten de cierta forma ciertos acuerdos.

${ }^{80} \mathrm{Al}$ respecto Whelan, P., The criminalisation of european cartel enforcement. Theoretical, legal, and practical challenges. p. 101-102, distinguiendo una serie de escenarios relevantes (declaración falsa y expresa de que no existe acuerdo entre competidores versus los casos, más comunes, en que se omite cualquier comunicación y no se niega expresamente la concurrencia de un acuerdo). En todos los casos la sanción requeriría que el 
consecuencia del acuerdo entre competidores y de esta forma afectar las expectativas de corrección en las operaciones respectivas ${ }^{81}$. Por último, Wardhaugh sostiene que para legitimar la utilización del Derecho penal para la protección de dichas expectativas, debiera ser apreciado el rol fundamental que esta jugaría como un instrumento de la justicia. En el marco de una sociedad liberal sería innegable la relevancia del mercado como mecanismo de distribución ${ }^{82}$.

En síntesis, de acuerdo con lo que se puede extraer de esta postura, los intereses que se verían afectados por la colusión serían intereses sociales generales derivados de la función que cumpliría el sistema de mercado en lo que respecta a la justicia en la distribución de bienes y servicios ${ }^{83}$. Tal valoración (es decir, su vínculo con la justicia) se centraría, en lo que alcanzo a ver, principalmente en la protección institucional debido a lo valiosa que resultaría, para la generalidad, que las decisiones relativas a la distribución de bienes y servicios se adopten por medio de las reglas del libre mercado y no por la intervención estatal centralizada. Por lo mismo, el énfasis está colocado en evitar la injerencia del Estado al menos en lo que respecta a la toma de decisiones en este ámbito. No obstante, si bien es cierto se debe reconocer la importancia de tal valor, no creo que resulte suficiente para justificar la intromisión del DPE para su protección. Aunque en definitiva esta propuesta satisface la necesidad de ofrecer un vínculo de los sistemas de mercado como institución con ciertas características o virtudes del mismo que propenden al desarrollo de los individuos, lo hace en forma tal que no daría cuenta de la protección de intereses que sean considerados fundamentales o imprescindibles para la consecución de este objetivo ${ }^{84}$.

Junto con lo anterior se centraría en la protección de expectativas relativas a la justicia o corrección de la forma como debieran llevarse a cabo las transacciones económicas y la afectación de las condiciones ideales de confianza en el mercado como mecanismo de

acuerdo se haga efectivo con efectos concretos en el precio de las cosas ofrecidas a los consumidores (forma de comunicar que el precio es el propio del mercado engañando a estos últimos).

${ }^{81}$ En Chile, en forma similar, Hernández Basualto, H., "La punibilidad de la colusión...", pp. 154155, aunque para efectos diversos, ha entendido las conductas colusivas secretas como una forma de engaño concluyente.

${ }^{82}$ Wardhaugh, B., Cartels, Market and Crime. A Normative Justification for the Criminalisation of Economic Collusion, p. 48.

${ }^{83}$ Según Martínez-Buján Pérez, C., “Algunas reflexiones sobre la moderna teoría del Big Crunch en la selección de bienes jurídico-penales (especial referencia al ámbito económico)”, en Anuario da Facultade de Dereito da Universidade da Coruña, 2003, p. 971, los intereses sociales generales serían aquellos "pertenecientes a la generalidad de las personas que integran una comunidad social”, y más precisamente se trataría, siguiendo la terminología propuesta por Bustos Ramírez, J., Obras Completas, T. II, Ara editores, Perú, 2005, p. 193, de un "bien jurídico institucional", en la medida que de esta postura se extraería que se protegerían determinadas instituciones básicas para el funcionamiento del sistema”, y que tenderían, en todo caso a "establecer vías o procedimientos organizativos-conceptuales para asegurar los bienes jurídicos individuales”.

${ }^{84}$ Se debe recordar, de acuerdo por ejemplo a Luzón Peña, D., Derecho Penal. Parte general, $3^{a}$ edición, B de F, Buenos Aires, 2016, p. 89 que en razón del principio de fragmentariedad el Derecho penal "no ha de proteger todos los bienes jurídicos ni penar todas las conductas lesivas de los mismos, sino solo los ataques más graves a los bienes jurídicos más importantes". 
distribución de bienes y servicios. Mas, resultaría igualmente insatisfactorio que el núcleo de la protección no atienda a los motivos por los que esas condiciones de confianza serían relevantes de cara a los intereses y límites propios del DPE. Nuevamente la referencia a tal efecto lesivo no sería suficiente para justificar la utilización del Derecho penal y sería necesario introducir nuevos criterios que permitieran complementar la misma. La razón de lo anterior vendría dada porque la mera referencia a la confianza en el buen funcionamiento del sistema no explicaría realmente la necesidad de acudir a la sanción penal, ya que el mantenimiento de tal confianza es una tarea del Derecho en general.

Por lo mismo, parece conveniente considerar, para resolver el problema planteado de la delimitación de intereses a proteger, que a propósito de las reglas de funcionamiento de los mercados surgirían expectativas legítimas para los consumidores relativas al mantenimiento de ciertos niveles de competencia que resultarían fundamentales debido a los efectos que se esperan en la fijación de los precios como mecanismo para la toma de decisiones de quienes pueden acceder a bienes y servicios ${ }^{85}$. A partir de lo anteriormente dicho se extrae que de la competencia económica efectiva, es decir, no tergiversada por parte de quienes se espera que compitan, y sus efectos en la fijación de precios surgirían en definitiva expectativas legítimas de facilitación para la participación y acceso a los mercados ${ }^{86}$. Si bien es cierto se podría reprochar que tal punto de partida no tomaría en cuenta que la decisión de optimizar la protección del consumidor debiera entenderse exclusivamente a propósito de la consecución de mayor eficiencia económica y no en aras del fomento de la participación, este reproche sería injustificado en la medida que confundiría intereses que debieran entenderse como propios del Derecho económico frente a aquellos que son de resorte del Derecho penal y restringiría, de esta forma, de manera injustificada los intereses que pudieran verse comprometidos con la colusión ${ }^{87}$. Como ha señalado Sen, por ejemplo, los sistemas de mercado como institución no solo podrían ser evaluados de cara a los conceptos de eficiencia económica ya vistos, sino que también en lo que respecta

${ }^{85}$ Conclusión que se extrae fácilmente si se observa el tratamiento extrapenal de la protección de la libre competencia. Refleja tal tendencia de priorizar lo que se conoce como "bienestar del consumidor" por encima del "bienestar total", Whelan, P., The criminalisation of european cartel enforcement. Theoretical, legal, and practical challenges, p. 98, y sus efectos en sede de justificación del reproche moral de la colusión. Ahora, y como se pudo apreciar, la protección de estos intereses no es absoluta, ya que un análisis detallado de los objetivos asociados a la legislación antimonopólica permitiría apreciar que si bien la protección de dicha expectativa es considerada en la actualidad como un objetivo prioritario debe ser complementada con otros objetivos relevantes, como puede ser el de alcanzar mayores niveles de eficiencia dinámica. Lo que, en definitiva, también traería como consecuencia, entre otras, un aumento de los niveles de satisfacción a los consumidores y sus posibilidades de elegir, pero no solo estas, sino que la promoción de intereses tan relevantes como el de la innovación productiva en lo que respecta al mejoramiento del cuidado del ecosistema, entre otras.

86 Tal punto de partida tampoco resultaría incompatible con las valoraciones extrapenales, como se ha podido ver más arriba a la hora de dar cuenta de la tendencia progresiva a reconocer la protección de los intereses de los consumidores como uno de los intereses prioritarios del Derecho de la competencia.

${ }^{87}$ Se debe tener en cuenta que el Derecho penal económico, en el ámbito comparado, no ha sido ajeno a la protección de ciertos intereses de los consumidores, cuando estos son especialmente relevantes. Así, por ejemplo, en España, por, entre otros, el delito de publicidad fraudulenta (art. $282 \mathrm{CP}$ ). 
a sus efectos en el fomento de las capacidades de las personas en relación con el acceso a bienes y servicios y, de esta manera, el aumento de sus posibilidades de desarrollo ${ }^{88}$.

Por una disminución de los precios que atienda a la confluencia de otros intereses relevantes, se permitiría que más personas puedan acceder a esos bienes y servicios y, en esta medida, aumentar sus opciones de desarrollo o capacidades. Por lo mismo, se justificaría que se intente prevenir aquellas conductas que distorsionen o alteren el funcionamiento de dichas reglas del mercado y que puedan anular la competencia misma o restringirla en forma que no cumpla con sus diversas funciones, ya que una de las razones por la que el sistema potencia tal institución, es la de posibilitar el acceso no distorsionado a bienes y servicios por parte de la ciudadanía como presupuesto para el desarrollo individual. En definitiva, y de cara a la satisfacción del principio de lesividad, la colusión podría tergiversar en tal forma las reglas del juego propias de los sistemas de mercado para la fijación de precios, que podría poner en peligro las posibilidades de participación de los ciudadanos en el tráfico económico, ya sea mediante la generación de una barrera de acceso a determinados mercados (es decir, podría representar un peligro de exclusión) o incluso una disminución de la capacidad adquisitiva de los consumidores ${ }^{89}$ (esto es, un peligro de imposición de cargas abusivas para el acceso $)^{90}$.

Esta propuesta traería, como se verá a continuación, consecuencias del todo relevantes en lo que respecta a la satisfacción de principios limitadores del ius puniendi como el de la subsidiariedad y el de la fragmentariedad. Como se señaló, no es objeto de este artículo un análisis detallado de todos los problemas asociados a la legitimidad de la criminalización de la colusión, sino solo aquellos que estuviesen relacionados al

${ }^{88}$ Creo que esta propuesta de delimitación de los intereses afectados por la colusión encontraría sólidos puntos de apoyo si se toma en cuenta lo señalado por Amartya K. Sen, el que critica que se evalúe los efectos esperados del mercado solo desde una perspectiva bienestarista propia del utilitarismo. Por el contrario, Sen propone que los logros esperados de un mercado competitivo se evalúen en razón de sus efectos en el fomento de las libertades individuales. Para eso propone un estándar diverso, centrado en la idea la libertad como oportunidad, en razón de que esta maximizaría las opciones de las personas para vivir del modo que elegirían. Entiende libertades individuales en dos facetas: de procesos y oportunidades. La faceta de proceso consiste en el procedimiento de decidir libremente por uno mismo. Se compone de la autonomía decisional en las elecciones a realizar y la inmunidad frente a las interferencias de terceros. La faceta de oportunidad se refiere a la capacidad real para conseguir las cosas que hemos decidido, sin importar mediante qué proceso se logra ello. Al respecto, fundamental Sen, A., Bienestar, justicia y mercado (trad. Salcedo, D.), Ediciones Paidós, Barcelona, 1998, pp. 123 y ss.

${ }^{89}$ En relación con los usualmente perjudicados por esta conducta, Stucke, M., "Morality and Antitrust", p. 504 .

${ }^{90}$ Cuando se señala que la gravedad de la conducta radica en la puesta en peligro de intereses colectivos fundamentales solo se está haciendo desde la perspectiva de la idoneidad de la misma para afectar el bien jurídico protegido. En este trabajo no se puede abordar el problema de las técnicas de tipificación que resultarían más adecuadas en el ámbito del Derecho penal económico, debido a que excede con creces el alcance propuesto en un comienzo. Además, la definición de si se criminaliza la colusión por medio de un delito de peligro, abstracto o concreto en su caso, es un problema interpretativo de tipos penales en particular. Por lo mismo, esta definición deberá hacerse en un estudio posterior centrado en los problemas interpretativos que puedan derivar del tipo penal que criminaliza la colusión en Chile. 
principio de lesividad y a las consecuencias que pudieran extraerse de la satisfacción de este requisito de cara a otros principios limitadores.

\section{A modo de CONCLusión: CONSECUENCIAS RElativas a la obSERVANCia a LOS LÍMITES DE SUBSIDIARIEDAD Y FRAGMENTARIEDAD DEL DERECHO PENAL}

Si se tiene en cuenta tal punto de partida, es decir, el del reconocimiento de la competencia económica como una institución valorada debido a sus consecuencias en sede de fomento de la participación en los mercados, y su respectivo efecto para el desarrollo de los individuos, puede ser más sencillo abordar el problema de la gravedad de la colusión como forma de agresión a los intereses ya identificados y que permitirían legitimar su criminalización.

En primer lugar, se abordarán las principales consecuencias en sede de fragmentariedad, esto es, la exigencia de que las decisiones de criminalización se restrinjan a conductas especialmente graves o intolerables contra los intereses protegidos ${ }^{91}$. De las reflexiones efectuadas con anterioridad se pueden extraer ciertas consecuencias que facilitarían la comprensión de la gravedad de la colusión y ciertas restricciones que se debieran tener en cuenta para su criminalización vinculadas a la delimitación de aquellos casos en que se pueda poner en riesgo o peligro los intereses protegidos. A su vez, se podría dar cuenta de aquellas características de la conducta que la hacen especialmente intolerable para la ciudadanía.

En lo que respecta a la gravedad de la misma de cara a la protección de los intereses en juego, se debe tener en cuenta la siguiente limitante. Si se parte de la base que la colusión resultaría especialmente grave debido a los peligros de exclusión y de imposición de cargas ya descritos, se debiera restringir su criminalización a los casos en que efectivamente los acuerdos de los productores y distribuidores sea idónea para esa puesta en peligro. Lo anterior trae como consecuencia que no cualquier acuerdo colusorio puede ser tenido como idóneo para dichos efectos, sino que solo en cuanto presente la entidad suficiente para incidir en la fijación del precio de los bienes y servicios por encima del nivel competitivo (lo que se conoce como "poder de mercado") ${ }^{92}$. Por tanto, se debiera restringir la sanción penal a los casos que impliquen una restricción o afectación relevante de la competencia. Esta conclusión se ve apoyada si se tiene en cuenta que los efectos lesivos de la colusión, abordados en sede extrapenal, se asocian en todo

91 Así, Luzón Peña, D., Derecho Penal. Parte general, $3^{\text {a }}$ edición, B de F, Buenos Aires, 2016, p. 88.

92 Es decir, no todo acuerdo entre productores o distribuidores es relevante, por ejemplo, si se analiza desde una perspectiva económica. Tal relevancia se determina atendiendo al concepto de "poder de mercado", esto es, y siguiendo a Motta, M., Competition Policy. Theory and Practice, Cambridge University Press, Cambridge, 2004 (reimpreso 2009), pp. 40-41, "la habilidad de una empresa para elevar los precios por encima del nivel competitivo". En esta sede no se pueden abordar problemas diversos, relativos a las exigencias de acreditación de tal situación, lo que es un problema específico de los tipos penales en cuestión. Tampoco se quiere decir con esto que el tipo penal recientemente incorporado en Chile exija la acreditación de tal situación. 
caso a una situación monopólica y sus eventuales efectos en la fijación de $\operatorname{precios}^{93}$ y no a la mera constatación de acuerdos para estos efectos. Solo en estas situaciones se produciría un peligro serio de que los consumidores no puedan acceder a dichos bienes y servicios por vías alternativas y se afecten sus posibilidades de participación en los términos ya abordados ${ }^{94}$.

En lo que respecta al problema de porqué la colusión (en los casos de afectación relevante de la competencia) resultaría especialmente intolerable para la ciudadanía, se debe considerar que tal criminalización supone reconocer que los efectos de alza de los precios deben ser entendidos como una transferencia indebida en beneficio de quien debió haber competido ${ }^{95}$. La misma resultaría injustificada porque las reglas del juego no respaldarían tal ganancia. A partir de acá se entiende que la colusión pueda ser comprendida como una injusticia intolerable. En primer lugar, porque reflejaría la obtención de una ganancia inmerecida, la que considerada en términos colectivos o generales, pueden llegar a ser realmente cuantiosas ${ }^{96}$. Pero, sobre todo, porque las ganancias obtenidas a expensas de los intereses de los consumidores sin mediar justificación adicional alguna, debieran ser entendidas como el resultado de un abuso del rol que desempeña quien se colude. Se puede entender como una forma de abuso debido a que en la actualidad no se puede desconocer que el Estado ha dejado en manos de los privados decisiones distributivas de suma relevancia, por lo que es razonable asumir que a mayor cuota de libertad para el desarrollo de actividades económicas y mayor conciencia de las consecuencias lesivas que puedan derivar de la misma, se refuerce el cumplimiento de aquellos deberes de evitar las mismas mediante la sanción penal.

En segundo lugar, esta forma de agresión resulta intolerable porque existiría mayor conciencia de que tal abuso podría afectar seriamente las posibilidades de participación y, por tanto, pondría en peligro las posibilidades de desarrollo de los perjudicados, lo que resultaría especialmente debido a que ya no se puede seriamente predicar la voluntariedad de los intercambios respectivos, ya que el consumidor, por lo general, se ve en

93 Así se podría explicar, por ejemplo, que el legislador chileno indique en el inc. $2^{\circ}$ del artículo 64 de la Ley N $\mathrm{N}^{\circ}$ 20.945, que "El Fiscal Nacional Económico deberá interponer querella en aquellos casos en que se tratare de hechos que comprometieren gravemente la libre competencia en los mercados".

${ }^{94}$ Un problema diverso, y que no puede ser abordado acá, debido a que excede el objeto de este artículo, está dado por la posibilidad de que el legislador diferencie entre niveles de gravedad y, por esta razón, decida sancionar con mayor pena ciertos hechos atendiendo a la relevancia que presenta el mercado del que se trate para el desarrollo de los individuos, lo que se podría presentar, por ejemplo, en los casos de bienes de primera necesidad.

95 Por tanto, si estamos frente a una ventaja indebida de quien restringe la competencia, o una desventaja injusta para sus víctimas. Esta, en definitiva, es una decisión política que solo puede resolverse mediante la priorización determinados objetivos. Al respecto, Whelan, P., The criminalisation of european cartel enforcement. Theoretical, legal, and practical challenges. p. 107. Acá, por ejemplo, vuelve a surgir el problema de si en definitiva son los consumidores finales o no quienes sufrirían los efectos de la colusión.

${ }^{96}$ Al respecto, Whelan, P., The criminalisation of european cartel enforcement. Theoretical, legal, and practical challenges, p. 94. Ver también, OECD, Fighting Hard Core Cartels: Harm, Effective Sanctions and Leniency Programmes, 2002, p. 90, disponible en web: https:/www.oecd.org/competition/cartels/1841891.pdf. 
la obligación de intervenir en tales intercambios ${ }^{97}$. Considerar que dichas conductas son siempre voluntarias y que, por tanto, este efecto sería el menos reprochable de la colusión, no resulta correcto, ya que en determinados casos los consumidores no tendrían una opción real de retiro de tales interacciones, debido a lo fundamentales que resultan para el desarrollo (lo que es claro, por ejemplo, en mercados relativos a bienes de primera necesidad). A partir de tal constatación se podría ahondar en la construcción de esta conducta como una forma de agresión contra esas expectativas, caracterizada por constituir un verdadero abuso de una posición de quien está en condiciones de determinar, de acuerdo al mismo sistema económico, quiénes pueden acceder a determinados bienes y servicios.

El hecho de que tal acceso se considere valioso hace que imponer cargas abusivas se torne especialmente reprochable, ya que, en definitiva, se podría ver en entredicho la capacidad de acceso de quienes hubieran podido participar habiéndose formado correctamente los precios, o porque se pondría en peligro la capacidad adquisitiva de quienes se han visto en la necesidad de interactuar en tal mercado. Si bien es cierto los efectos de la colusión, en lo inmediato, podrían no ser significativos en términos individuales, esto no significa que no se trate de una conducta sumamente peligrosa, debido a los efectos nocivos que podría tener a largo plazo en los consumidores ${ }^{98}$.

Solo queda por vincular, a modo de una primera aproximación, la propuesta efectuada con las consecuencias que se podrían extraer para la determinación de si tal protección se puede alcanzar o no a través de un medio menos lesivo que la imposición de la sanción penal, con el objeto de verificar si se satisfacen las exigencias provenientes del principio de subsidiariedad ${ }^{99}$. Lo primero que se debe tener en cuenta es que desde una perspectiva propiamente disuasoria o preventiva, es decir, aquella que se concentra en determinar la sanción más eficiente para prevenir la comisión del delito, se suele sostener que una sanción diversa a la sanción penal (específicamente la pena privativa de libertad) como podría ser las propias del Derecho administrativo, resultarían insuficientes, ya que solo esta última sería una pena individual que no resultaría indemnizable o asegurable ${ }^{100}$, por tanto, no podrían ser traspasados sus efectos a otra persona.

${ }^{97}$ Exigir al consumidor que sustituya en todo caso el bien o servicio puede resultar, a su vez, una carga de enorme intensidad que dificultaría, a su vez, que pueda abstraerse de la transacción abusiva respectiva.

${ }^{98}$ Lo anterior es especialmente evidente para los casos de acuerdos clandestinos o secretos para parte de los partícipes de la interacción económica. Se debe considerar que este nivel de justificación solo puede abordarse en forma adecuada recurriendo al conocimiento de los economistas y la evaluación de los efectos de disminución de la eficiencia distributiva derivados de la colusión.

99 En relación con el contenido de este principio, Ossandón Widow, M., "La formulación de tipos penales. Valoración crítica de los instrumentos de técnica legislativa”, Editorial Jurídica de Chile, Santiago, 2009, pp. 425-426.

${ }^{100}$ Así, por ejemplo, Mañalich Raffo, JP., “CCárcel para la colusión? Seis opiniones” (Bergoeing Vela, R., Sierra Iribarren, L.), Puntos de referencia, edición online $\mathrm{N}^{\circ} 409$, Centro de Estudios Públicos, 2015, p. 5. Disponible en web: http://www.cepchile.cl/cep/site/artic/20160304/asocfile/20160304101409/ pder409_RBergoeing-LSierra.pdf, Última visita: 21/12/2016, la pena privativa de libertad es una sanción esencialmente personalísima, en tanto es una "privación de un derecho que no es susceptible de ser compensada por equivalencia ni de ser transferida a personas diferentes sobre la cual se impone y ejecuta la sanción en cuestión”. Tal argumento fue considerado en la tramitación de la Ley No 20.945, así, por ejemplo, Aldo 
No obstante, y en esto radica la vinculación anunciada, en la medida que exista mayor conciencia por parte de la ciudadanía acerca de la importancia de los intereses que se verían afectados por la colusión, la relación directa que la protección de la libre competencia tendría con el fomento de sus posibilidades de participación en el ámbito socioeconómico y la gravedad de la colusión para esos intereses, la conducta ya no podría ser vista como una mera infracción de las reglas relativas al modo de llevar a cabo una actividad o profesión ${ }^{101}$, sino que se podría entender con la entidad suficiente para su criminalización ${ }^{102}$. Es esta la razón que aconsejaría que no se reaccione con sanciones que sean traspasables a otra persona, o asegurables, en la medida que el mensaje comunicativo que emanaría del Estado no sería coincidente con la importancia que debiese asignarse al interés protegido, ni podría ser considerada como una reacción efectiva de cara a los propios fines del DPE enunciados en un comienzo.

\section{BIBLIOGRAFÍA}

ADHAR, R., "Consumer, redistribution of income and the purpose of competition law", ECLR, 2002 , v. 23.

Ayal, A., Fairness in Antitrust: Protecting the Strong from the Weak (Kindle Edition), Hart Publishing, Oxford and Portland, Oregon, 2014.

BAKer, J., "Economics and Politics: Perspectives on the Goals and Future of Antitrust", Fordham Law Review, Vol. 81, 2013.

González, (profesor de economía de la Universidad de Chile) sostuvo que el efecto de la pena privativa de libertad "es altamente disuasivo, en tanto la multa administrativa, aunque sea personal, podría ser asegurable por alguien. En cambio, es improbable o muy difícil que la pena de cárcel se traspase a otra persona”. Siguiendo la misma línea, Francisco Agüero (Director del Centro de Regulación y Competencia de la Facultad de Derecho de la Universidad de Chile), expuso: "la cárcel es un disuasivo enfocado en las personas que permite detectar los carteles, a diferencia de las multas que se centran en las compañías, salvo escasas excepciones. Además, la cárcel afecta la reputación personal y empresarial del individuo, y la libertad perdida no puede ser restituida por el dinero”. Ambas opiniones en: Informe de la comisión de economía, fomento, MIPYMES, protección de los consumidores y turismo de la Cámara de Diputados, en boletín 9950-03. Disponible en https://www.camara.cl/pley/pley_detalle.aspx?prmID=10362 Última visita 21/12/2016. Para un análisis detallado, Whelan, P., The criminalisation of european cartel enforcement, pp. $44 \mathrm{y}$ ss.

101 Así, Kindhäuser, U., “Acerca de la legitimidad de los delitos de peligro abstracto...”, p. 443, sostiene que el Derecho penal económico, "solo es legítimo cuando reacciona ante infracciones que no son simplemente contrarias a las reglas de ordenación política del modo de ejercer una profesión”. Al respecto, en relación con el problema de la protección de la competencia, García Cavero, P., de acuerdo con la protección de la competencia se puede limitar al Derecho administrativo sancionador "mientras la conciencia colectiva lo considere una mera infracción de las reglas de juego en el mercado, pues en la medida en que comience a destacarse el efecto nocivo que estas prácticas producen en el mercado y finalmente en el bienestar de los consumidores, la persecución puramente administrativa, por más severa que sea, no bastará para satisfacer las demandas sociales de castigo", pp. 10-11.

102 En un sentido similar Mañalich, Raffo, JP., “¿Cárcel para la colusión?...”, p. 6, sostiene que “parece inconsistente reconocer en la colusión un atentado particularmente grave y socialmente dañoso contra las bases del tráfico económico y al mismo tiempo impugnar la razonabilidad de su criminalización mediante su penalización con una sanción de encarcelamiento”. 
BANFi del Río, C., Responsabilidad civil por competencia desleal. Estudio de derecho chileno y comparado, Legal Publishing, Thomson Reuters, Santiago, 2013.

Bassa Mercado, J.; Viera Álvarez, C., "Un nuevo giro hermenéutico de la Corte Suprema en la aplicación del recurso de amparo económico”, Revista de Derecho de la Pontificia Universidad Católica de Valparaíso, XXXVIII, 2012.

Berggren, N., "The Benefits of Economic Freedom. A Survey”, The Independent Review, vol. VIII, n. 2, 2003 .

Blair, R.; Sokol, D., "Welfare standards in U.S and E.U. Antitrust Enforcement", Fordham Law Review, vol. 81, 2013.

Botтke, W., “Criminalidad económica y Derecho criminal económico en la República Federal de Alemania” (trad. Arroyo Alfonso, Soledad), Revista Penal, No 4, 1999.

Bustos Ramírez, J., Obras Completas, T. II, Ara editores, Perú, 2005.

Carnevali Rodríguez, R., “Algunas reflexiones en relación a la protección penal de los bienes jurídicos supraindividuales”, en Revista Chilena de Derecho, Vol. 27, num. 1, 2000.

Cseres, K., "The controversies of the Consumer Welfare Standard", The Competition Law Review, Vol. 3, 2007.

Daвван, M., International and Comparative Competition Law, Cambridge University Press, Cambridge, 2010.

Daskalova, V., "Consumer Welfare in EU Competition Law: What Is It (Not) About?", The Competition Law Review, vol. 11, 2015.

DEY Degere, M., The interface between Competition Law, and other EU public policies and their objectives. Tesis de magister, Universidad de Lovaina, año académico 2010-2011.

DiEz Ripollés, José Luis, La racionalidad de las leyes penales, Edit. Trotta, Madrid, 2003.

Duhne, N., Competition Law and Economic Regulation. Making and Managing Markets, Cambridge University Press, Cambridge, 2015.

Estrada i Cuadras, Albert, "Presente y futuro del delito de alteración de precios (art. 284 Cp)", InDret, 2014.

Feijoo Sánchez, B., Cuestiones actuales de Derecho penal económico, B de F, Buenos Aires, 2009.

FEıjoo Sánchez, B., "Imputación objetiva en el Derecho penal económico y empresarial. Esbozo de una teoría general de los delitos económicos”, InDret, 2009.

Fermandois Vöhringer, A., Derecho constitucional económico, 2ª edición, Ediciones UC, Santiago, 2006.

Ferrada Bórquez, Juan Carlos, "La constitución económica de 1980. Algunas reflexiones críticas”, Revista de Derecho, Vol. XI, 2000, p. 51.

García Cavero, P., Derecho Penal Económico. Parte general, $3^{\text {a }}$ edición, Jurista Editores, Lima, 2014.

García Cavero, P., Los delitos contra la competencia, ARA editores, Lima, 2004.

Green, S., Mentir, hacer trampas y apropiarse de lo ajeno. Una teoría moral de los delitos de cuello blanco (trad. Agustina Sanllehí, J., Amorós Bas, M., Ortiz de Urbina Gimeno, I.), Marcial Pons, Madrid, 2013.

Haines, F.; Beaton-Wells, C., "Ambiguities in Criminalizing Cartels. A Political Economy”, Brit. J. Criminol., 52, 2012.

Hernández Basualto, H., "Perspectivas del Derecho penal económico en Chile”, en Revista Persona y Sociedad, XIX, 2005.

Hernández Basualto, H., "La punibilidad de la colusión (secreta) de precios en el derecho chileno”, Política Criminal, Vol. $7, \mathrm{~N}^{\circ} 13$.

Kaplow, L., "On the Choice of Welfare Standards in Competition Law", Harvard Law School, Discussion Paper, num. 693, p. 19. disponible en web: http://www.law.harvard.edu/programs/olin_center/papers/pdf/Kaplow_693.pdf. 
Kerber, W., "Should Competition Law Promote Efficiency? Some Reflections of an Economist on the Normative Foundations of Competition Law", Marburg Papers on Economics, num. 09-2007, disponible en web https://www.uni-marburg.de/fb02/makro/forschung/gelbereihe/ artikel/2007-09_kerber.pdf

Kikwood, J., Lande, R., "The Fundamental Goal of Antitrust: Protecting Consumers, Not Increasing Efficiency”, Notre Dame Law Review, vol. 84, 2008.

Kindhäuser, U., "Acerca de la legitimidad de los delitos de peligro abstracto en el ámbito del Derecho penal económico”, Hacia un Derecho penal económico europeo. Jornadas en honor del Prof. Klaus Tiedemann (trad. Molina Fernández, F.), Madrid, Boletín Oficial del Estado, 1995.

KindhäUser, U., "Estructura y legitimación de los delitos de peligro abstracto", InDret, 2009. LaO, M., "Ideology Matters in the Antitrust Debate", Antitrust Law Journal, vol. 79, 2014.

LIANOS, I., "Some reflections on the question of the goals of UE Competition Law", CLES Working Paper Series, 3/2013, pp. 13 y ss., disponible en web: https://www.researchgate.net/publication/256053279_Some_Reflections_on_the_Question_of_the_Goals_of_EU_Competition_Law.

Luzón Peña, D., Derecho Penal. Parte general, $3^{a}$ edición, edit. B de F, Buenos Aires, 2016.

Maier-Rigaud, F., "On the normative foundations of competition law -efficiency, political freedom and the freedom to compete", The Goals of Competition Law, Edward Elgar Publishing, Cheltenham, UK, Northampton, USA, 2012.

MARTínez Buján, C., "Algunas reflexiones sobre la moderna teoría del Big Crunch en la selección de bienes jurídico-penales (especial referencia al ámbito económico)”, Anuario da Facultade de Dereito da Universidade da Coruña, 2003.

Martínez Buján, C., Derecho Penal Económico y de la Empresa, Parte General, 5 a edición, edit. Tirant Lo Blanch, Valencia, 2016.

Mayer Lux, L.; Fernándes Godinho, I., "La estafa como delito económico", Revista de Derecho de la Pontificia Universidad Católica de Valparaíso, vol. XLI, 2013.

Morales Godoy, J.; Zavala Ortiz, J., Derecho económico, 5ª edición, Legal Publishing Thomson Reuters, Santiago, 2013.

Motta, M., Competition Policy. Theory and Practice, Cambridge University Press, Cambridge, 2004 (reimpreso 2009).

Ossandón Widow, M., La formulación de tipos penales. Valoración crítica de los instrumentos de técnica legislativa, Editorial Jurídica de Chile, Santiago, 2009.

Paredes Castañón, J., "Los delitos de peligro como técnica de incriminación en el derecho penal económico: bases político-criminales", Revista de derecho penal y criminología. num.11, enero 2003.

SAtz, D., Por qué algunas cosas no deberían estar en venta. Los límites morales del mercado (trad. Salas, H.), Siglo XXI Editores, Argentina, 2015.

SEN, A., Bienestar, justicia y mercado (trad. Salcedo, D.), Ediciones Paidós, Barcelona, 1998.

Stucke, M., "Morality and Antitrust", Columbia Business Law Review, Vol. 4, 2006.

Stucke, M., "What is competition?", en, Zimmer, D. (editor), The Goals of Competition Law, Edward Elgar Publishing, Cheltenham, UK, Northampton, USA, 2012.

Tiedemann, K., "Presente y futuro del Derecho penal económico", Hacia un Derecho penal económico europeo. Jornadas en honor del Prof. Klaus Tiedemann (trad. Suárez González, C., Lascuraín Sánchez, J., Cancio Meliá, M.), Boletín Oficial del Estado, Madrid, 1995.

Tiedemann, K., Manual de Derecho penal económico. Parte general y especial (trad. Hernández Basualto, H.), Tirant lo Blanch, Valencia, 2010.

VAnger, V., "Consumer Welfare, Total Welfare and Economic Freedom-On the normative Foundations of Competition Policy", Freiburg Discussion Papers on Constitutional Economic, 
09/3, Institut für Allgemeine Wirtschaftsforschung, disponible en web: http://www.eucken. de/fileadmin/bilder/Dokumente/Diskussionspapiere/09_03bw.pdf.

Vega Gutiérrez, J., Mercado de valores y Derecho penal, B de F, Edisofer s.l., Buenos Aires, 2013. Waked, D., "Antitrust Goals in Developing Countries: Policy alternatives and Normative Choices”, Seattle University Law review, vol. 38, 2015.

Wardhaugh, B., Cartels, Market and Crime. A Normative Justification for the Criminalisation of Economic Collusion, Cambridge University Press, Cambridge, 2014.

Whelan, P., The criminalisation of european cartel enforcement. Theoretical, legal, and practical challenges, Oxford University Press, Oxford, 2014.

Whish, R., Bailey, D., Competition Law, 8a edición, Oxford University Press, Oxford, 2015.

Wright, J., D.; Ginsburg, D., “The Goals of Antitrust: Welfare Trump’s Choice”, Fordham Law Review, vol. 81, 2013.

Zabala, C., Los delitos bursátiles, La Ley (Kindle Edition), España, 2011. 